\title{
pFPL Vectors for High-Throughput Protein Localization in Fungi: Detecting Cytoplasmic Accumulation of Putative Effector Proteins
}

\author{
Xiaoyan Gong, ${ }^{1}$ Oscar Hurtado, ${ }^{1}$ Baohua Wang, ${ }^{1}$ Congqing Wu, ${ }^{1}$ Mihwa Yi, ${ }^{2}$ Martha Giraldo, ${ }^{2}$ \\ Barbara Valent, ${ }^{2}$ Michael Goodin, ${ }^{1}$ and Mark Farman ${ }^{1}$ \\ ${ }^{1}$ Department of Plant Pathology, Plant Sciences Building, 1405 Veteran's Dr., University of Kentucky, Lexington, KY 40546, \\ U.S.A.; ${ }^{2}$ Department of Plant Pathology, 4024 Throckmorton Plant Sciences Center, Kansas State University, Manhattan, \\ 66506, U.S.A.
}

Submitted 19 May 2014. Accepted 5 October 2014.

As part of a large-scale project whose goal was to identify candidate effector proteins in Magnaporthe oryzae, we developed a suite of vectors that facilitate high-throughput protein localization experiments in fungi. These vectors utilize Gateway recombinational cloning to place a gene's promoter and coding sequences upstream and in frame with enhanced cyan fluorescent protein, green fluorescent protein (GFP), monomeric red fluorescence protein (mRFP), and yellow fluorescent protein or a nucleus-targeted mCHERRY variant. The respective Gateway cassettes were incorporated into Agrobacterium-based plasmids to allow efficient fungal transformation using hygromycin or geneticin resistance selection. $m R F P$ proved to be more sensitive than the GFP spectral variants for monitoring proteins secreted in planta; and extensive testing showed that Gateway-derived fusion proteins produced localization patterns identical to their "directly fused" counterparts. Use of plasmid for fungal protein localization (pFPL) vec-

The pFPL plasmids are available from the addgene plasmid repository under accession numbers 61647 through 61655 .

Current address for X. Gong: Beijing Jing-Meng Stem Cell Technology Co., Ltd., 6th Floor, Building B, Shangdi East Rd 5-2, Haidian District, Beijing 100085, China

Current address for O. Hurtado: Pioneer Hi-Bred International, 7300 NW 62nd Ave., Johnston, IA 50131, U.S.A.

Current address for B. Wang: College of Plant protection, Fujian Agriculture and Forestry University, Fuzhou, Fujian 350002, China.

Current address for $\mathrm{C}$. Wu: Graduate Center for Nutritional Sciences, College of Medicine, University of Kentucky, Lexington, 40536, U.S.A.

Current address for M. Yi: Forage Improvement Division, The Samuel Roberts Noble Foundation, Ardmore, OK 73401, U.S.A.

Current address for M. Giraldo: University of Puerto Rico-Mayaguez, Estacion Experimental Agricola de Corozal HC-5, Box 10322, Corozal PR. 00783-9713.

Corresponding author: Mark Farman; Telephone: +1.859 .218 .0728 ; Fax: +1.859.323.1961; E-mail: farman@email.uky.edu

* The $\boldsymbol{e}$-Xtra logo stands for "electronic extra" and indicates that seven supplementary figures, three supplementary tables, and supplementary protocols are published online.

(C) 2015 The American Phytopathological Society tors with two different selectable markers provided a convenient way to label fungal cells with different fluorescent proteins. We demonstrate the utility of the pFPL vectors for identifying candidate effector proteins and we highlight a number of important factors that must be taken into consideration when screening for proteins that are translocated across the host plasma membrane.

The availability of genome sequences for many plant-pathogenic fungi opens the door to functional genomic studies whose collective goals are to identify large numbers of genes with roles in pathogenesis. Currently, there is an intense focus on the identification and characterization of fungal or oomycete effector proteins. After in planta secretion by the pathogen, these proteins may be retained in the plant extracellular space (apoplastic effectors) or they may be translocated across the host plasma membrane and into the cytoplasm (cytoplasmic effectors), where they are believed to interfere with the host's resistance machinery (Park et al. 2012; Shabab et al. 2008). Effectors are considered key players in the pathogenic process.

Candidate oomycete and fungal cytoplasmic effectors can sometimes be identified based on the presence of conserved translocation signals (Jiang et al. 2008; Rafiqi et al. 2010), which are proposed to interact with phospholipid components of the plasma membrane (Kale et al. 2010), thereby promoting protein uptake into the host cell. Unfortunately, many fungal pathogens have no obvious translocation motifs in their predicted protein sets and, in this case, effector candidates must be identified using functional screens. A key criterion implying effector activity is a protein's ability to translocate across the plant cell membrane and accumulate in the host cytoplasm. This is easily (and most convincingly) established using livecell, in planta imaging of fungal strains expressing effector candidates sporting a fluorescent protein (FP) tag (Khang et al. 2010; Ribot et al. 2013). However, scaling up such experiments for genome-wide screens is not a trivial undertaking due to the large numbers of secreted proteins encoded by a typical fungal genome. Accordingly, such endeavors are greatly facilitated by using efficient, high-throughput assay pipelines.

We recently completed a large-scale secreted protein localization project for the rice blast fungus Magnaporthe oryzae, with the goal of identifying putative effectors and other secreted proteins with possible roles in pathogenesis. The blast 
fungus executes a hemibiotrophic style of plant infection, in which each successive plant cell invasion is biotrophic but individual invaded cells are no longer viable by the time the fungus moves into the next cell (Kankanala et al. 2007). Magnaporthe effectors lack recognizable translocation motifs and many known effectors are specifically expressed during plant invasion. Therefore, the success of the project was dependent on the creation of new tools for the efficient production of FP fusion constructs and their subsequent expression in the fungus during plant infection. Traditional approaches to the generation of fungal protein::FP fusions utilize three basic methods: i) engineering a restriction enzyme site just before the stop codon of the protein of interest, followed by ligation to an FP gene cut with the same enzyme (Kershaw and Talbot 2009; Khang et al. 2010; Mosquera et al. 2009); ii) using fusion polymerase chain reaction (PCR) (He et al. 2012; Yon and Fried 1989; Yu et al. 2004); or iii) gap repair recombinational cloning in Saccharomyces cerevisiae (Ma et al. 1987) to generate precise translational fusions (Bourett et al. 2002; Dagdas et al. 2012). The first two methods are not ideal for high-throughput studies because they entail multiple PCR or enzyme treatment and fragment purification steps to generate the end construct. Although in vivo recombination cloning using yeast allows the generation of constructs in a two-step procedure, it has the disadvantage that yeast colonies are slower growing than Escherichia coli. Additionally, should switching between FP markers with very different sequences (such as green fluorescent protein [GFP] and red fluorescent protein [RFP]) be required, yeast-based recombination cloning must be repeated from scratch.

Gateway cloning uses an in vitro recombination reaction to generate recombinant DNA molecules with very few prior manipulation steps (Hartley et al. 2000). It has the added advantage that, once a desired construct has been made, the gene of interest can easily be shuttled between different Gateway-compatible vectors. Recognizing the power of Gateway cloning for high-throughput functional studies in plants, Goodin and coworkers generated a comprehensive collection of Gateway cloning vectors (Chakrabarty et al. 2007) that are now in wide use among the plant research community (Dietzgen et al. 2012; Jeong et al. 2010; Levy et al. 2013; Selote and Kachroo 2010). To facilitate our screening for effector candidates, we utilized the Gateway FP cassettes from the pSITE-C vector series and incorporated them into the binary vector pBHt2, which is commonly used for efficient Agrobacterium tumefaciens-mediated transformation (ATMT) of fungi (Jackson et al. 2009; Kemski et al. 2013; Nyilasi et al. 2005; Rho et al. 2001; Rolland et al. 2009; Talhinhas et al. 2008).

Here, we demonstrate the utility of the plasmids for fungal protein localization ( $\mathrm{pFPL}$ ) for identifying candidate Magnaporthe effector proteins that are delivered into and accumulate within the host cell cytoplasm. We also introduce a complementary set of vectors specifying geneticin resistance that allow dual labeling with two different FP markers. Finally, we provide a series of robust protocols allowing efficient use of the pFPL vectors for high-throughput protein localization studies in fungi.

\section{RESULTS}

\section{Vector construction.}

Four base plasmids were developed allowing the production of protein fusions to enhanced cyan fluorescent protein (eCFP), enhanced (e)GFP, monomeric (m)RFP, or enhanced yellow fluorescent protein (eYFP) (hereafter abbreviated to CFP, GFP, RFP, and YFP). These plasmids are named with the pFPL prefix and identifiers for the $\mathrm{FP}(\mathrm{C}, \mathrm{G}, \mathrm{R}$, or $\mathrm{Y})$ and se- lectable marker ("h" for hygromycin resistance). The plasmids lack promoter sequences upstream of the Gateway cassette because they are designed to drive fusion protein expression from the native gene promoter. This allows the user to monitor both expression and localization patterns simultaneously and also reduces the likelihood that overexpression could lead to mislocalization. Maps of the base vectors are shown in Figure $1 \mathrm{~A}$.

Use of the Gateway technology for generating protein fusions necessitates incorporation of the attB2 recombination sequence between the coding regions for the protein-of-interest (POI) and the FP. In the pFPL vectors, the attB2 sequence is part of a 51-nucleotide linker, which means that the POI is separated from the FP by a 17-amino-acid spacer (Fig. 1B).

\section{Efficient and economical production of FP fusions.}

The utility of the pFPL plasmids for high-throughput studies is dependent on amplifying large numbers of genes with high efficiency. Depending on the criteria used to define secreted proteins, the $M$. oryzae secretome comprises upward of 800 proteins (Chen et al. 2013; Choi et al. 2010) with diverse functions, and these are encoded by genes whose sizes range from less than $300 \mathrm{bp}$ to more than $4 \mathrm{~kb}$. A number of steps were taken to maximize the efficiency with which the secreted protein genes (plus approximately $1 \mathrm{~kb}$ of native promoter) were amplified. i) With the intention of reducing nonspecific binding, as well as primer costs, "half-attB" adaptors were added to the $5^{\prime}$ end of each gene-specific primer $\left(5^{\prime}\right.$ primer adaptor: AAAAAGCAGGCTTA and $3^{\prime}$ primer adaptor: AGAAAGCT GGGTA). The complete attB sequences were added in a second round of PCR. ii) To ensure that the extension times were appropriate for all targets, the PCR plates or strips were configured to contain reactions targeting similarly sized products. iii) To optimize annealing across the plate or strip, we utilized a novel and extremely robust touchdown PCR protocol that entailed using an initial annealing temperature of $56^{\circ} \mathrm{C}$ (all primers were designed to have similar melting temperatures) and then reducing the annealing temperature by $0.2^{\circ} \mathrm{C}$ at each and every round of 25 cycles.

Amplification products of the correct sizes were sequenced to confirm their veracity but, due to the high-throughput nature of the project, it was not economically feasible to generate complete sequences for products longer than approximately $1.5 \mathrm{~kb}$. Therefore, to minimize the likelihood of PCR-generated mutations, we used a high-fidelity polymerase and analyzed the available sequence information to check for any mutations in the portion of the gene or promoter that was sequenced.

In combination with the other steps, the novel touchdown PCR method proved to be extremely successful: among 326 genes selected for amplification in one set of experiments, 282 $(87 \%)$ were successfully amplified on the first attempt and another 21 were amplified on the second try, resulting in an overall success rate of $93 \%$. Once the primary PCR products were sequence verified, the complete Gateway "tails" were added, using full-length attB1 and attB2 primers in a second round of PCR.

Streamlining of entry clone or destination clone production was accomplished by performing BP and LR clonase reactions in a single tube. After electrotransformation of $E$. coli with the reaction mix, the bacterial cell suspension was divided in two, with one half being plated on Luria-Bertani (LB) + zeocin (for entry clone recovery) and the other on LB + kanamycin (for destination clone recovery). In this manner, a 5-day procedure for sequential entry to destination clone production was reduced to 3 days. A complete, stand-alone protocol for Gateway clone production is provided in Supplementary text. 


\section{Efficient integration of intact fusion constructs} into the fungal genome.

With high-throughput studies, it is not feasible to analyze every transformant to ensure that each one receives an intact fusion construct. Therefore, it was important first to establish the frequency with which transformants receive an intact gene. To this end, we extracted DNA from a number of representative transformants and digested the DNA samples with two restriction enzymes: $M l u \mathrm{I}$, which cuts within the TrpC terminator $\left(\mathrm{T}_{\operatorname{TrpC}}\right)$, and a second enzyme that cuts the in the vector upstream of the cloned gene but not in the gene itself or in the GFP reporter. Thus, hybridization with a GFP:: $\mathrm{T}_{\mathrm{TrpC}}$ probe should yield at least two hybridizing fragments: one, corresponding to the cloned gene::GFP:: $\mathrm{T}_{\mathrm{TrpC}}$ fragment (Supplementary Fig. S1A), has a predictable size and should be shared by different transformants carrying the same gene; the other fragment contains the right border and its size will vary, due to random T-DNA insertion within the genome. Where possible, two independent transformants were analyzed per gene, thereby simplifying the interpretation of the Southern blot results.

In all, 15 of 23 transformants analyzed yielded two hybridizing fragments, consistent with the insertion of a single transgene. Only one strain (36-2) lacked hybridization signals with the GFP:: $\mathrm{T}_{\mathrm{TrpC}}$ probe and rehybridization of the membrane with a hygromycin gene probe also produced no signals for this strain (results not shown). Thus, we conclude that this was a false transformant or it harbored a mitotically unstable transgene. In most cases, the two transformants carrying the same gene::GFP construct shared a hybridizing fragment whose size corresponded to the length of the predicted gene::GFP:: $\mathrm{T}_{\mathrm{TrpC}}$ restriction fragment. This indicated that the region spanning from the vector through the target gene and GFP reporter and into the terminator was intact. An exception was transformant 10-2, which lacked the 3.6-kb predicted fragment that was present in transformant 10-1. Presumably, transformant 10-2 integrated a T-DNA with an extensive right border truncation that extended well into the terminator fragment. Overall, however, the Southern hybridization data indicated that the majority of transformants (88\%) contained at least one copy of the intact fusion construct. Only five transformants (1-2, 4-2, 5-2, 10-1, and 12-2) produced three or more hybridization signals, indicative of multiple insertions, with the latter three transformants yielding patterns consistent with insertion of additional constructs that were truncated.

\section{Comparison of different FP for detection of fungal proteins in planta.}

At the outset of the project, we had limited information about the absolute expression levels of the proteins under study. For this reason, it was essential that the FP marker be detectable at as low a protein concentration as possible. However, we had no prior knowledge of the relative fluorescence intensities of

A

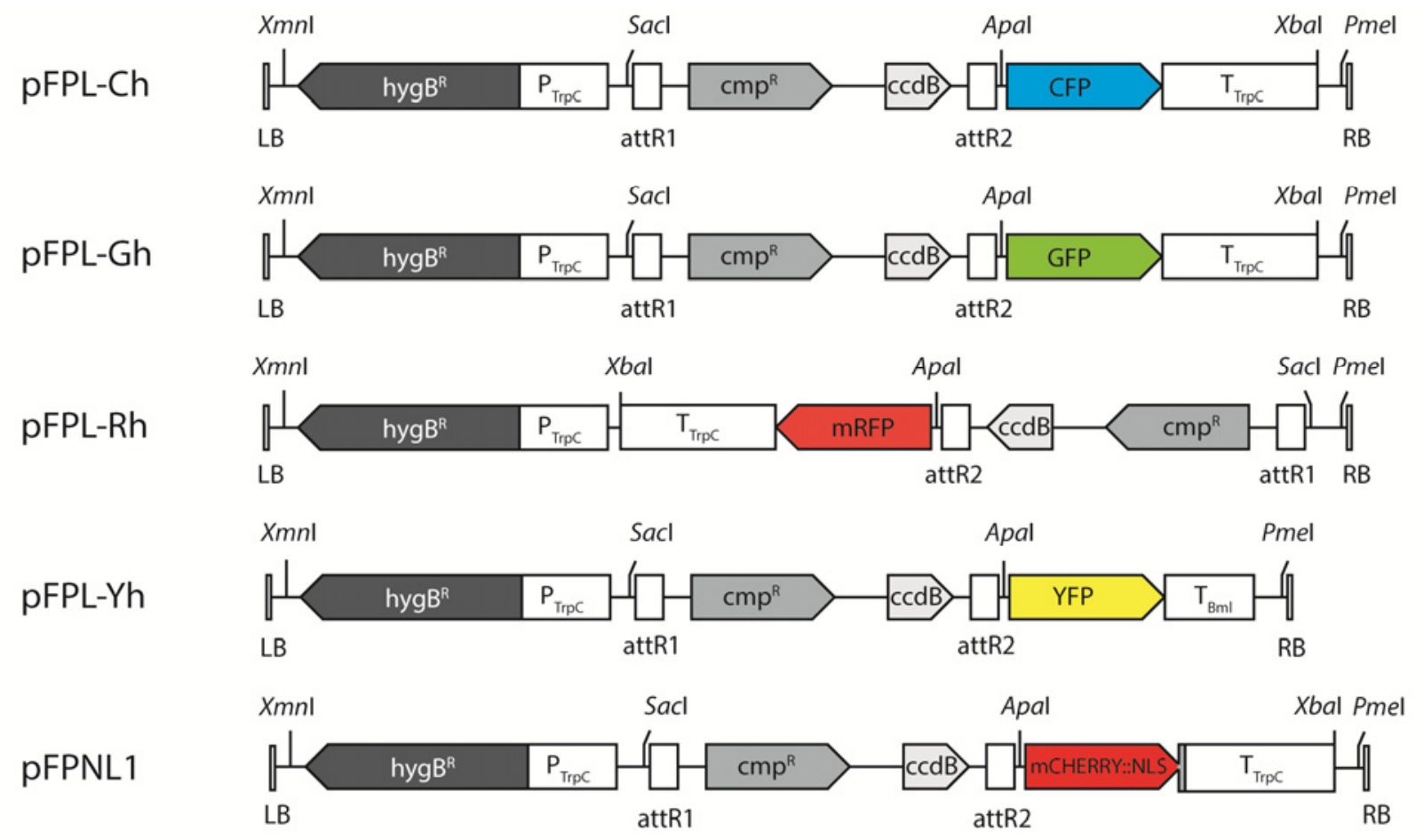

\section{B}
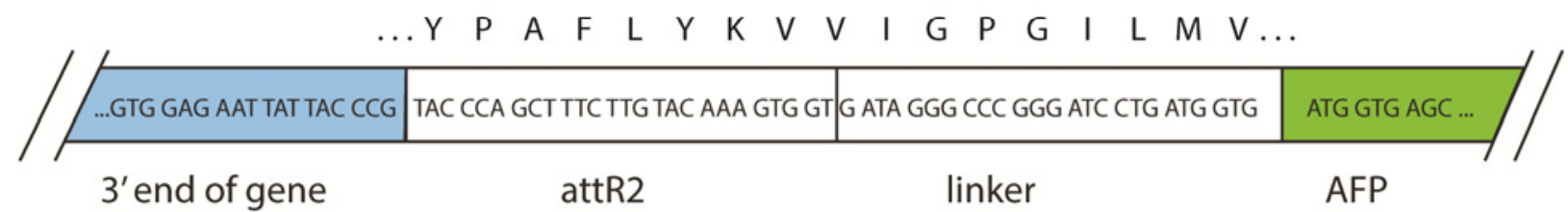

Fig. 1. Illustrations of the various pFPL constructs. A, Fluorescent proteins (FP) are shown in their respective colors. The gray box at the $3^{\prime}$ end of the mCHERRY gene represents a nuclear localization signal. $\mathrm{LB}=$ left border, hygB ${ }^{\mathrm{R}}=$ hygromycin $\mathrm{B}$ resistance gene, $\mathrm{P}_{\mathrm{GAPDH}}=$ promoter from Aspergillus nidulans glyceraldehyde-3-phosphate dehydrogenase gene, $\mathrm{P}_{\mathrm{TrpC}}=$ promoter from $A$. nidulans $\operatorname{TrpC}$ gene, $\mathrm{cmp}^{\mathrm{R}}=$ chloramphenicol resistance gene, $\mathrm{ccdB}=$ $c c d B$ suicide gene, $\mathrm{CFP}=$ cyan fluorescent protein, $\mathrm{GFP}=$ green fluorescent protein, $\mathrm{RFP}=$ red fluorescent protein, $\mathrm{YFP}=$ yellow fluorescent protein, $\mathrm{T}_{\mathrm{TrpC}}=$ terminator from A. nidulans $\operatorname{Trp} C$ gene, $\mathrm{T}_{\mathrm{Bml}}=$ terminator from Neurospora crassa $\beta$-tubulin gene, $\mathrm{RB}=$ right border. All features are drawn to scale. $\mathbf{B}$, Nucleotide and amino acid sequences of the attR2 region and additional linker between the FP and the gene cloned between the attR1 and attR2 sites. 

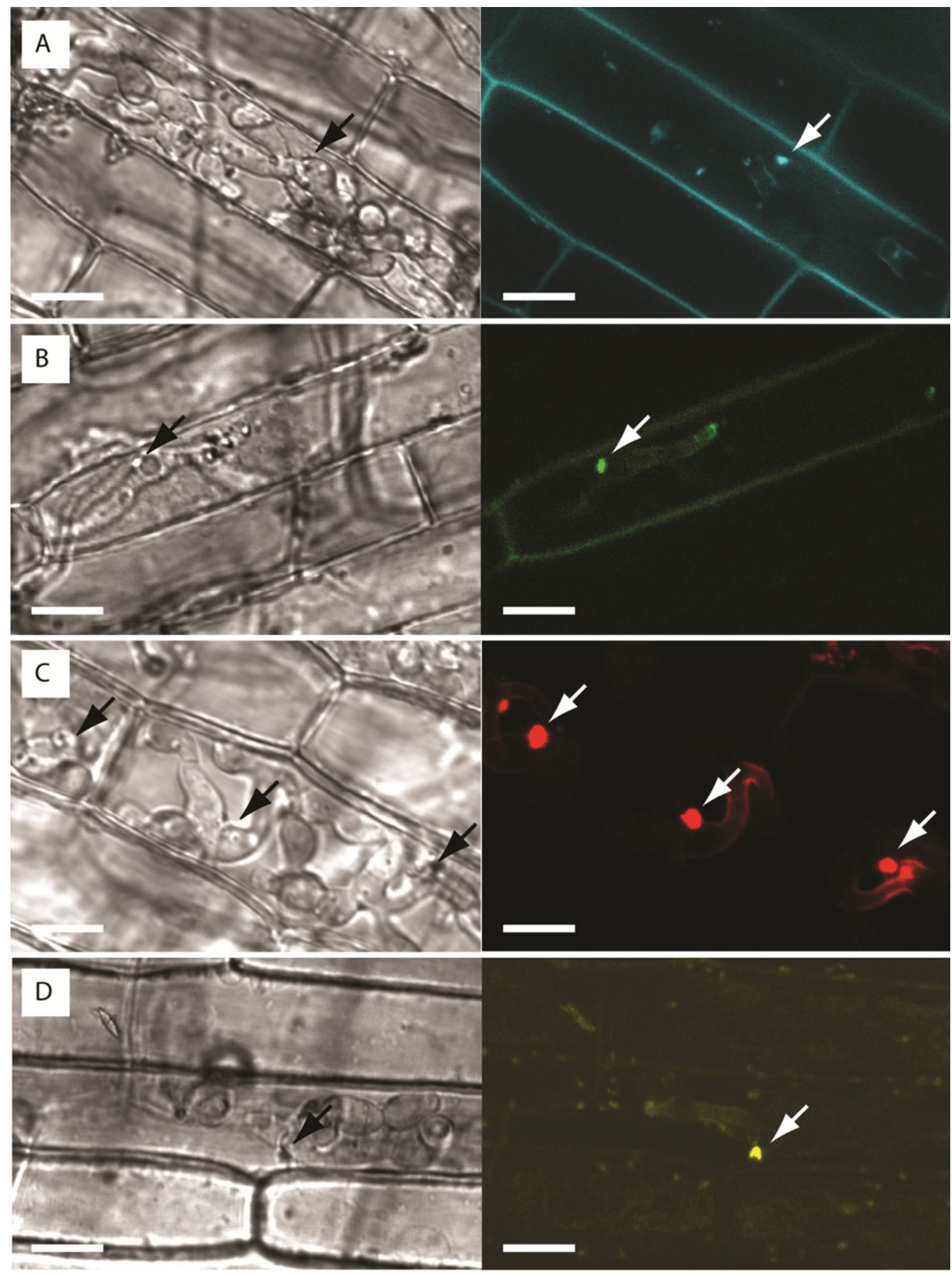

Fig. 2. Comparison of four different pFPL vectors. MGG_04795p (Bas1p) (Mosquera et al. 2009) was fused to fluorescent proteins (FP) using Gateway technology. Transformants were used to inoculate leaf sheaths of rice '51583' and visualization was performed $36 \mathrm{~h}$ postinoculation using epifluorescence microscopy. Images on the left-hand side are differential interference contrast; the right-hand side shows the FP: A, CFP; B, GFP; C, RFP; and D, YFP. Biotrophic interfacial complexes (BIC) are indicated with white arrows. Note that transformants producing the CFP, GFP, and YFP fusion proteins produced weak BIC fluorescence that was typically observed together with strong autofluorescence from the host cell walls and, in the case of YFP, also from the host cytoplasm and subcellular structures. RFP yielded much stronger signals in the BIC and surrounding the primary hyphae and could be observed with little or no autofluorescence. Scale bars $=20 \mu \mathrm{m}$. 
the various spectral variants within fungal or plant cells, especially when used to tag proteins that are destined for secretion.

A direct comparison of the four FP was made by fusing each one to the highly expressed biotrophy-associated secreted protein, Bas1p (MGG_04795p) (Mosquera et al. 2009). Magnaporthe transformants harboring the different constructs were used to inoculate rice leaf sheaths. After $36 \mathrm{~h}$, the sheaths were sectioned and protein expression was visualized using confocal microscopy. Bas $1 p$ is preferentially expressed in biotrophic hyphae and accumulates in biotrophic interfacial complexes (BIC). The protein was detectable with all four FP (Fig. 2). However, by far the strongest signals were obtained when it was fused to RFP. Significant fluorescence is visible at the cell periphery in the CFP, GFP, and YFP channels (Fig. 2A, B, and $\mathrm{D}$, respectively) and but not during RFP detection (Fig. 2C). Because we were working with secreted proteins, we considered the possibility that this pattern derives from apoplastic accumulation of the fusion proteins. However, imaging of the wild-type O-137 parent strain frequently yielded similar fluorescence patterns (Supplementary Fig. S2A), pointing to cell wall autofluorescence as the probable cause. It is important to note that such autofluorescence was sporadic in nature and, with RFP, was usually completely absent even when the cells contained extensive fungal growth. In general, cell wall autofluorescence was observed much more frequently during detection of CFP, GFP, or YFP fusion proteins (approximately $80 \%$ of infection sites; $n=253$ ), compared with only $36 \%$ of the time $(n=244)$ when imaging RFP fusions (Supplementary Table S1).

Plasmid pFPL-Rh has the FP in reverse orientation relative to the other vectors (Fig. 1A), which raised the possibility that the fluorescence intensity was influenced by the FP cassette's orientation. To test this idea, we generated a pFPL-Yh2 version with the Gateway:YFP cassette in reversed orientation and used this vector to generate an MGG_04795 (Bas1p)::YFP fusion. Live-cell imaging of Magnaporthe transformants expressing the "forward" and "reversed" fusion protein constructs showed no differences in fluorescence intensity (results not shown).

We suspected that the different FP might fluoresce at different intensities depending on their cellular locations. Therefore, to determine whether the results obtained for Bas $1 p$ represent a general trend, we performed an empirical study in which selected proteins were randomly fused to CFP, GFP, RFP, or YFP. Protein expression or distribution was then examined in spores $(0 \mathrm{~h})$, in mature appressoria formed on rice leaf sheath epidermis (approximately $18 \mathrm{~h}$ after inoculation), and in biotrophic hyphae growing inside the first invaded epidermal cell (approximately $36 \mathrm{~h}$ after inoculation). There was a striking difference in the proportion of genes that showed fluorescence with the different FP. The best results were obtained with RFP, which yielded fluorescent signals for $65 \%$ of the proteins $(n=$ 235) analyzed (Supplementary Table S2). The next best was GFP, which produced fluorescence when fused to $41 \%$ ( $n=$ 64) of proteins. CFP and YFP produced fluorescence with only $24 \%(n=17)$ and $33 \%(n=3)$ of the proteins analyzed, respectively. Several GFP-tagged proteins showed no fluorescence, despite the fact that their corresponding genes had already been shown to be expressed quite abundantly in planta (Mosquera et al. 2009). This suggested that CFP, GFP, and YFP are sometimes incapable of reporting on the localization of certain proteins even when they are expressed. To test this possibility, a number of proteins that had been linked to CFP or GFP and which had failed to show fluorescence were subsequently fused to RFP (via mobilization of the relevant pDONR cassettes into pFPL-Rh) and retested. Among 59 proteins that were reexamined, 19 (32\%) were successfully detected using
RFP fluorescence. As controls, 13 proteins that did fluoresce when GFP tagged were retested as RFP fusions. All 13 were successfully detected based on RFP fluorescence (results not shown).

\section{Fungal autofluorescence.}

Confocal imaging of wild-type, untransformed appressoria in the GFP channel revealed an interesting autofluorescent structure. Z sections near the top of the cell showed fluorescence in a bipartite, lip-like pattern (Supplementary Fig. S3A). As the confocal plane was moved downward toward the appressorium's base, the two areas of fluorescence contracted and converged until they were tightly focused in a single "thread" at or near the plane of plant cell contact. Note also the weak autofluorescence in the appressorial cell wall.

Appressoria were not the only fungal structures to exhibit autofluorescence. In one experiment, transformants carrying RFP-tagged versions of two proteins (MGG_08537p, a predicted endoglucanase precursor; and MGG_09095p, a predicted $\alpha$-L-arabinofuranosidase) exhibited bright fluorescence in the cell wall at the bases of emerging germ tubes but not in spores, appressoria, or biotrophic hyphae. Based on the predicted protein functions, germ tubes seemed like a reasonable place for these proteins to accumulate. However, when the experiment was repeated, a large number of transformants carrying various different secreted protein::RFP fusions exhibited the same fluorescence pattern, as did the untransformed, wildtype strain. Upon subsequent investigation, we observed the same pattern in archived images of wild-type spores, although the fluorescence intensity was much weaker. Curiously, this germ tube autofluorescence was very inconsistent because it was observed only in a very few $(<1 \%)$ imaging experiments.

\section{Validation of localization patterns produced by the Gateway-derived fusion proteins.}

The pFPL vectors contain a 17 -amino-acid linker between the protein of interest and the FP (Fig. 1B). To be sure that these amino acids do not alter the stability or distribution of certain proteins, we compared the localization patterns for a number of Gateway-derived protein fusions with their directly fused counterparts. The direct fusions were created by engineering unique restriction sites at the $3^{\prime}$ end of each secreted protein gene and a corresponding site at the start of the FP gene. The fusion constructs were then generated using standard cloning procedures. Proteins were selected to represent a range of distribution patterns, including cell membrane, vacuole, spore cell wall and septa, spore tip cell, BIC, biotrophic hyphal outlining, and endoplasmic reticulum. Multiple, independent transformants were analyzed to ensure that the results were representative.

Examples of the localization patterns obtained with the Gateway versus direct fusion methods are shown in Figure 3 and the results are summarized in Table 1 . For every gene that was tested, the method that was used to fuse the protein of interest to the FP had no detectable effect on the patterns of protein accumulation or the observed fluorescence intensity.

\section{Generation of dual-labeled Magnaporthe strains.}

Often it is useful to perform colocalization experiments using proteins labeled with different fluorescent markers. To facilitate such studies, we developed a complementary set of vectors in which the hygromycin resistance cassette was replaced with a geneticin (G418) resistance gene driven by the Aspergillus nidulans GAPDH gene promoter (Supplementary Fig. S4). To test the utility of these vectors, we performed colocalization experiments to follow up on the distribution of a fusion protein (MGG_01009::RFP) that exhibited reticulate 
staining patterns throughput the fungal cells, with characteristic fluorescent rings surrounding a circular, nonfluorescent area (Fig. 4B). We suspected that the protein was localizing to the endoplasmic reticulum (ER) and that the ring structures were the perinuclear ER. To confirm that the rings were surrounding the nucleus, we generated a Magnaporthe histone H1::GFP fusion in the pFPL-Gg vector (G418 resistance) and used this construct to retransform a strain expressing MGG_01009::RFP. Live-cell imaging of RFP and GFP distribution under the confocal microscope confirmed that the red rings surrounded circular, green fluorescent structures (Fig. 4D), consistent with perinuclear ER and nuclear labeling, respectively.
GATEWAY FUSION

A MGG_10315p

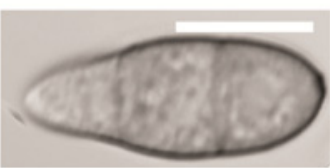

B MGG_09134p
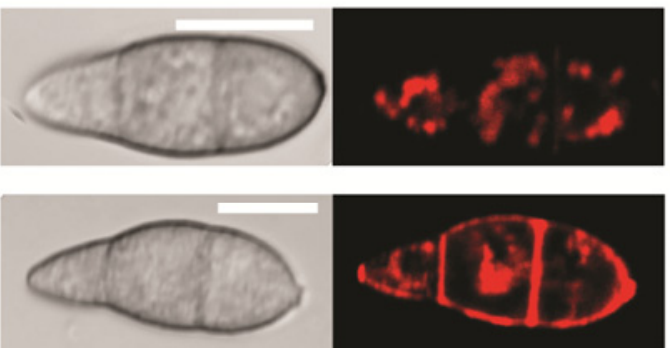

C MGG_09470p (Mlc1p)
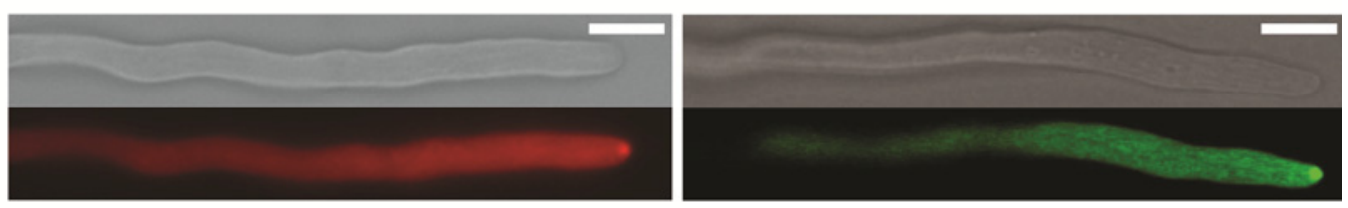

DMGG_06722p

$18 \mathrm{~h}$

$36 \mathrm{~h}$
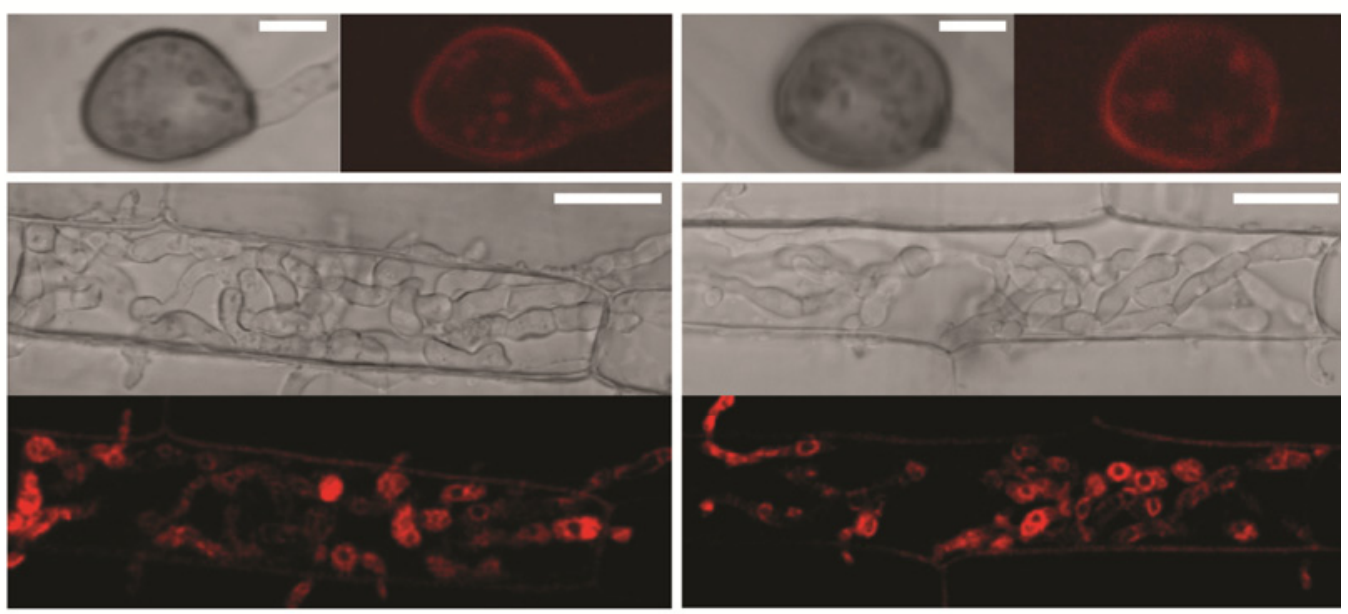

E MGG_02546p

$28 \mathrm{~h}$
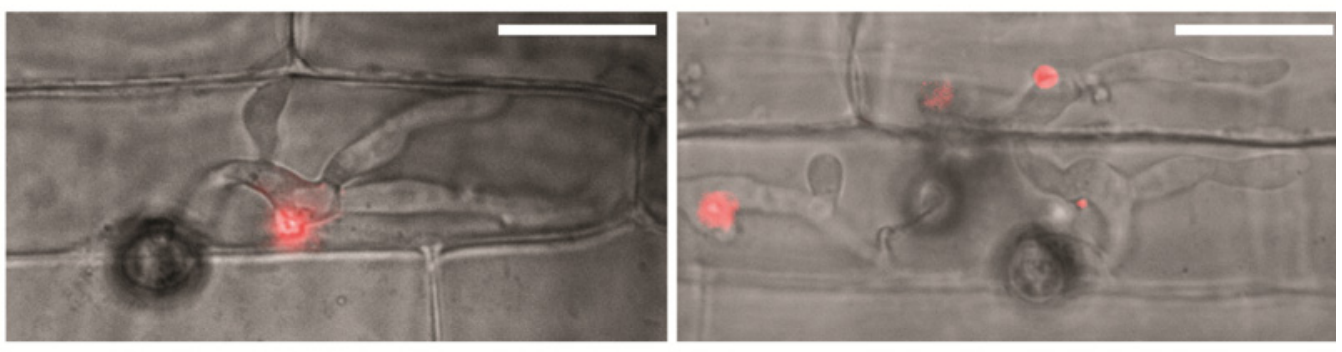

F MGG_10914 (Bas4p) $28 \mathrm{~h}$
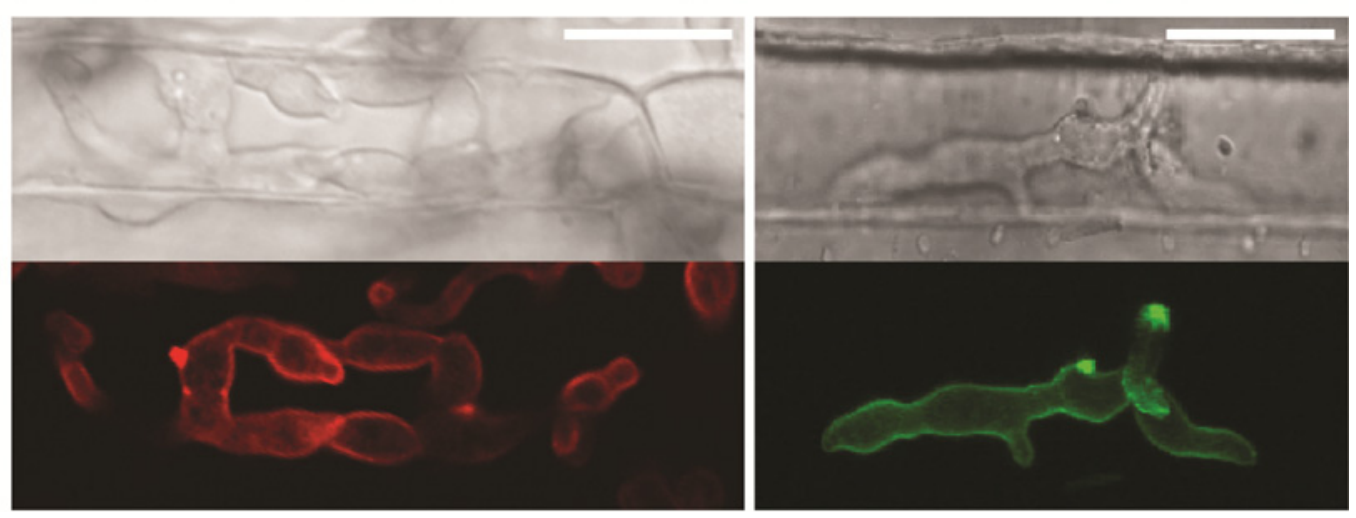


\section{Detecting delivery of fungal proteins into the host cell cytoplasm.}

Fungal plant pathogens secrete "effector" proteins that are often translocated into the cytoplasm of the invaded cell (Khang et al. 2010), where it is believed they promote pathogen invasion and interfere with host resistance. Here, we demonstrate the utility of the pFPL-Rh vector for detecting $M$. oryzae effector translocation and we highlight a number of important issues that should be considered when conducting such screens. In $M$. oryzae, effectors that are delivered into the host cytoplasm accumulate in BIC after secretion (Khang et al. 2010; Mosquera et al. 2009). Consequently, proteins that showed BIC accumulation were considered good translocated effector candidates and special attention was then paid to fluorescence occurring at the plant cell periphery, where the cytoplasm of most plant cells is located. As an example, the candidate effector MGG_02546p reached high concentrations in $\mathrm{BIC}$ and in regions of host cytoplasm near to where hyphae crossed cell walls to move into adjacent cells (Fig. 5A, white arrows with black outlines). Additionally, cytoplasmic accumulation was clearly signaled by the presence of fluorescent blebs along the cell wall, at positions distant from the fungal hyphae (Fig. 5A, plain white arrows). This blebby accumulation pattern is quite distinct from what is typically observed with cell wall autofluorescence, which tends to be more linear. In the case of MGG_02546::RFP, each infected cell contained one particularly large fluorescent bleb, where the protein was present in an ovoid structure. We suspect that this pattern represents accumulation within host nuclei that are appressed against the cell wall and, for this reason, we have labeled these structures "N" in Figure 5A and B. Note, however, that we reserve further discussion on the exact nature of these structures until we have more definitive evidence that they are, in fact, nuclei.

By definition, translocated effectors should traverse an intact plasma membrane. It follows that screens for translocated effectors should include a test for membrane integrity. We routinely used a plasmolysis test, which involved repeated wick- ing of a sucrose solution under the coverslip and looking for the subsequent appearance of plant protoplasm "balloons" which resulted from the decrease in turgor pressure. These balloons, which consist of plasma membrane, cytoplasm, nucleus, and tonoplast enveloping the central vacuole, were easily detected and, more importantly, cytoplasmic protein accumulation was clearly signaled by retraction of the fluorescence pattern in concert with the balloons (Fig. 5B).

Visualization of simple FP fusions, along with plasmolysis tests, are sufficient to detect cytoplasmic accumulation of highly expressed effectors such as MGG_02546p (see above) and Pwl2 (Khang et al. 2010). However, translocated effectors with lower expression levels might be diluted below the level of detection in the host cell cytoplasm. To increase detection sensitivity, Khang and coworkers developed an mCHERRY reporter with a nuclear localization signal (NLS) to concentrate translocated protein in the host nucleus. To facilitate highthroughput screening for weakly expressed proteins that are delivered into host cells, we developed a Gateway version of the mCHERRY:NLS reporter in which the FP::NLS cassette from plasmid pBV589 was used to replace the GFP gene in pFPL-Gh (Fig. 1E). The resulting vector, pFPNL1, was tested by using it to fuse the $P w l 2$ gene to the mCHERRY::NLS reporter. Imaging of a transformant expressing this fusion construct resulted in clear accumulation of the Pwl2:mCHERRY: NLS fusion protein in the nuclei of infected cells and in neighboring, uninfected cells (Fig. 5C, left-hand panel). Moreover, the intensity of fluorescence was similar to what was observed with the direct fusion (Fig. 5C, right-hand panel).

With some proteins, fluorescence was observed throughout the entire cell lumen. This pattern consistently occurred in host cells after the invasive hyphae had moved into neighboring cells, as exemplified by the BIC-localized $M$. oryzae cerato platanin homolog Msp1 p(MGG_05344p) (Jeong et al. 2007) (Fig. 5D). Because the cytoplasm of a healthy plant cell occupies an extremely thin layer adjacent to the cell walls, we suspected that the whole lumenal fluorescence pattern was indicative of a

Fig. 3. Comparison of localization patterns obtained with Gateway fusions versus "direct" fusions. Proteins were selected to represent a range of different localization patterns. The Gateway fusions were generated using the standard protocol. Direct fusions were constructed using a typical gene fusion strategy in which a unique restriction site was engineered at the $3^{\prime}$ end of the target gene and the start of the red fluorescent protein (RFP) gene. Spores were imaged on microscope slides. All other images are from inoculated rice leaf sheaths and were acquired at the time points indicated. A, MGG_10315p shows diffuse fluorescence in probable endoplasmic reticulum (ER). Scale bars $=10 \mu \mathrm{m}$. B, Putative hydrophobin, MGG_09134p, is visible in the ER and accumulates in septa. Scale bars $=10 \mu \mathrm{m}$. C, MGG_09470p, a Magnaporthe myosin light chain protein and Spitzenkörper marker, is concentrated at hyphal tips. Scale bars $=2 \mu \mathrm{m}$. D, MGG_06722p, a $\beta$-1,3-glucosanyltransferase, accumulates in the appressorial wall and is present in appressorial vesicles. In biotrophic hyphae, it is abundantly present in the ER. Scale bars = $5 \mu \mathrm{m}$ for appressoria and $20 \mu \mathrm{m}$ for hyphae. E, Hypothetical, small, secreted protein MGG_02546p is found in biotrophic interfacial complexes (BIC). F, MGG_10914p (Bas4p) (Mosquera et al 2009) is strongly expressed in biotrophic hyphae, is present in BIC, and accumulates in the interface between the fungal cell wall and the plant membrane that envelops it. Scale bars $=20 \mu \mathrm{m}$. All images are from individual confocal $\mathrm{Z}$ sections, with the exception of those in $\mathrm{E}$, which are epifluorescence.

Table 1. Localization patterns for fusion proteins used in comparisons of Gateway cloning versus direct ligation

\begin{tabular}{|c|c|c|}
\hline Protein & Predicted function & Localization pattern \\
\hline MGG_10315p & Hydrophobin & Vesicles \\
\hline MGG_02546p & Putative effector & Biotrophic interfacial complex (BIC) \\
\hline MGG_05344p & Predicted protein & Cell wall \\
\hline MGG_09134p & Hypothetical protein & Spore septa \\
\hline MGG_06722p & 1,3- $\beta$-Glucosanyltransferase & Endoplasmic reticulum \\
\hline MGG_04795p & Bas1p (putative effector) & $\mathrm{BIC}$ \\
\hline MGG_09693p & Bas $2 \mathrm{p}$ (putative effector) & BIC, cell wall crossing points \\
\hline MGG_11610p & Bas $3 p$ (putative effector) & BIC, cell wall crossing points \\
\hline MGG_10914p & Bas $4 p$ (putative effector) & Hyphal outlining \\
\hline MGG_00987p & Similar to plasma membrane protein involved in G-protein mediated pheromone signaling & Plasma membrane \\
\hline MGG_06064 & Class VII chitin synthase & Spore tip cell, appressorial vesicle ring ${ }^{\mathrm{a}}$ \\
\hline MGG_09470p & Myosin regulatory light chain cdc4 & Spitzenkörper \\
\hline
\end{tabular}

${ }^{a}$ Direct fusion was not performed for MGG_06064 as part of the current project but results for a direct fusion were reported previously by Odenbach and associates (2009). 


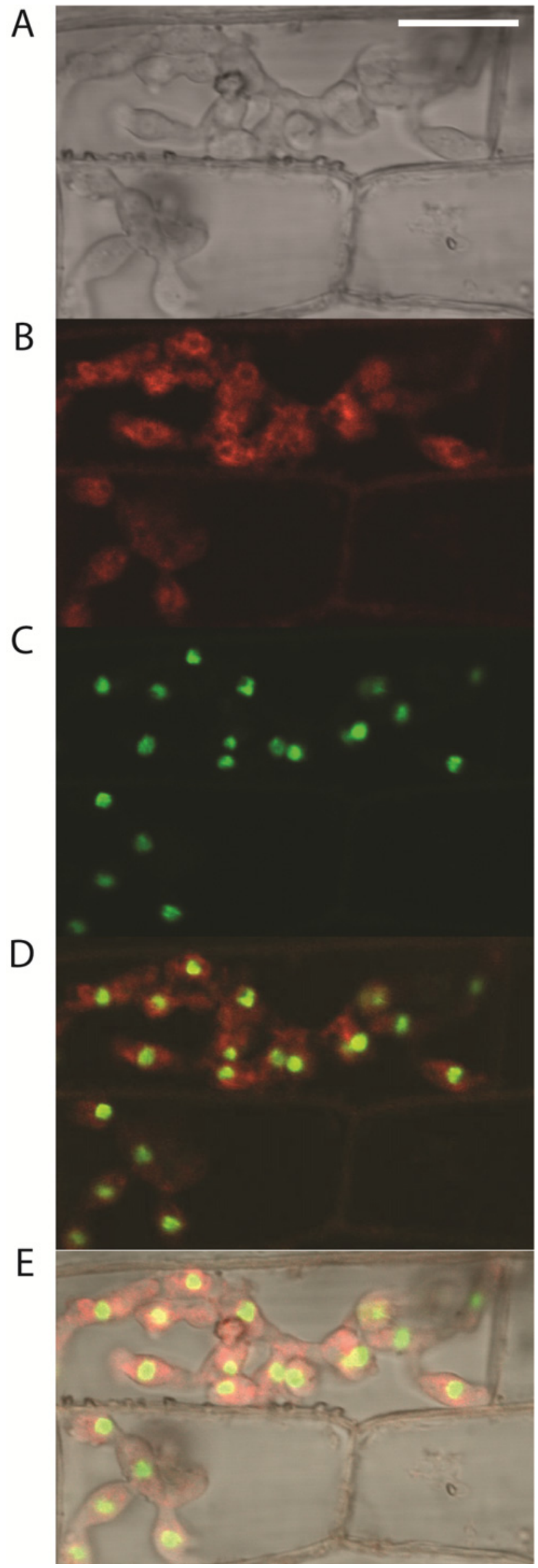

loss in host cell integrity. Plasmolysis tests confirmed this suspicion because, whereas uninfected cells and newly infected cells showed the appearance of protoplast balloons, plasmolysis induced no change in the lumenal fluorescence patterns (Fig. 5D). Only once did we observe Msplp::RFP fluorescence outside BIC in the retracted cytoplasm of a plasmolyzed cell (Supplementary Fig. S5). In this instance, the hyphal growth was fairly advanced and the protoplast "balloon" was extensively "stretched" across the invading hyphae.

One has to be careful when interpreting cytoplasmic fluorescence in heavily infected cells because even prototypical apoplastic effectors such as Bas $4 p$ can be detected in the cytoplasm of such cells following plasmolysis. In such instances, however, the Bas4p fluorescence pattern changes from even outlining to punctate staining (Khang et al. 2010; Mosquera et al. 2009), possibly indicating a loss of membrane integrity. Therefore, to test whether punctate Bas4p patterns are associated with compromised membranes, we treated healthy, plasmolyzed cells with a 5\% Triton X-100 solution in an attempt to induce membrane leakiness. Surprisingly, this failed to affect membrane integrity, as shown by the persistence of protoplast balloons (Supplementary Fig. S6A). However, subsequent wicking of a $50-\mu$ drop of $10 \%$ sodium dodecyl sulfate solution under the coverslip resulted in an immediate loss of protoplast integrity and an instantaneous change in Bas $4 p$ localization from even hyphal outlining to punctate foci. This effect was dramatic and repeatable.

While localizing the AVR1-CO39p effector, Ribot and coworkers (2013) saw "pockets" of fluorescence at the corners and ends of invaded cells. Such fluorescence was very "smooth" in appearance and showed no obvious organellar structure. In the absence of supporting plasmolysis data, we suspected that these cells might have been naturally plasmolyzed and that the fluorescence was actually in the apoplast. To test this alternative interpretation, we performed plasmolysis experiments on rice cells showing similar fluorescence pockets during early infection with a fungal strain expressing MGG_02546::RFP. Wicking of a sucrose solution under the coverslip caused the pockets to retract away from the cell wall, thereby confirming their cytoplasmic nature (Supplementary Fig. S7). Here, it is worth noting that we also observed these cytoplasmic pockets in uninfected cells; therefore, they do not appear to be strictly an outcome of infection.

\section{DISCUSSION}

Here, we describe the development of a suite of Gateway vectors for high-throughput protein localization in fungi. These vectors provide the means for efficient generation of target protein:FP fusions and utilize the target protein's native promoter sequences for expression. Consequently, the resulting fusion constructs report not only on protein location but also on pat-

Fig. 4. Simultaneous localization of two different proteins. A Magnaporthe oryzae transformant carrying MGG_01009p (endoplasmic reticulum-localized) fused to red fluorescent protein (RFP) in pFPL-Rh (hygromycin resistance) was retransformed with pFPL-Gg (specifying geneticin resistance) carrying a green fluorescent protein (GFP)-tagged histone H1 gene (MGG_12797). Transformants were inoculated on rice leaf sheaths (rice 'YT-16') and imaging was performed approximately 48 h postinoculation. A, Differential interference contrast image; B, RFP channel; C, GFP channel; D, RFP and GFP merged image; E, DIC, RFP, and GFP channels merged. Note the characteristic circles in the RFP image (B). These likely correspond to perinuclear endoplasmic reticulum as indicated by the localization of the nuclear marker, histone H1::GFP (C through E). Scale bar $=20 \mu \mathrm{m}$. 
terns of protein expression. Studies revealed that a number of proteins with different localization patterns produced equivalent results whether fused via the Gateway linker or directly through engineered restriction sites. Thus, these vectors should produce results that are comparable with existing technologies.

We chose to use the ATMT-compatible, pBHt2 plasmid backbone (Mullins et al. 2001) because ATMT transformation of $M$. oryzae is efficient and reliable, whereas protoplast transformation suffers from strain-to-strain or protoplast batch variability. pBHt2 has been successfully used to transform a number of different fungi, indicating that the pFPL vectors should have broad utility. Should ATMT be unfeasible for a given fungus, in most cases, it ought to be possible to use the fusion construct (in a circular or linear form) for polyethylene glycolmediated transformation of protoplasts.

With high-throughput studies, it is impractical to screen every transformant for the integrity of the inserted fusion construct. It is known that T-DNA insertion in Magnaporthe spp. produces frequent left-border truncations, whereas right borders tend to remain intact (Choi et al. 2007; Meng et al. 2007). Therefore, the vectors were designed to minimize the generation of hygromycin-resistant colonies containing truncated fusions by incorporating the Gateway:FP cassettes adjacent to the right border. The rationale was that selection of hygromycin-resistant transformants should automatically filter out leftborder truncations that extend into the test cassettes. This was borne out by Southern hybridization analysis of selected transformants, which confirmed that the majority of transformants contained at least one intact MGG::FP::terminator cassette.

\section{Relative fluorescence intensity.}

FP have been widely used to study the localization of fungal proteins, with GFP usually being the reporter of choice. However, because our goal was to examine the localization patterns of as many proteins as possible and their expression levels were essentially unknown, the success of the project depended on using the FP with the greatest detection sensitivity. Through empirical experimentation and direct comparisons, we discovered that RFP is a more reliable marker than CFP, GFP, or YFP for detection of fungal secreted proteins. This was surprising because GFP has three times the quantum yield of RFP and is twice as photostable (Shaner et al. 2005) and, therefore, ought to yield stronger fluorescence signals. The improved performance of RFP also cannot be explained by differences in $\mathrm{pKa}$ $(\mathrm{RFP}=4.5$ and GFP $=6)($ Shaner et al. 2005) because the fungal vacuolar lumen (where many secreted proteins were localized) and the plant apoplast are both at approximately $\mathrm{pH} 6$ (Felle 1998; Gao et al. 2004; Grignon and Sentenac 1991; Hesse et al. 2002), which ought to favor GFP detection. One possible explanation for GFP's reduced fluorescence is its requirement of an oxidizing environment for protein maturation (Miyawaki et al. 2003). Additionally, RFP has a predicted O-glycoslylation signal near its carboxy terminus, whereas GFP lacks such signals (data not shown). This may make RFP more resistant to degradation within the secretory system.

Importantly, we were able to detect RFP-tagged proteins in a number of cellular locations within the fungus (cytoplasm, plasma membrane, cell wall, septa, spore tip mucilage, Spitzenkörper, vesicles, vacuoles, and the ER) and in infected host cells (BIC, outlining the hyphae, cell wall crossing points, within the host cell cytoplasm, and even within the host cell nucleus). Thus, RFP is a robust marker for in planta studies of fungal secreted protein expression or localization.

\section{Unexpected and sporadic autofluorescence.}

Not only was the RFP reporter the most effective for fungal protein detection but also imaging in the RFP channel yielded the least amount of autofluorescence from plant cells infected with biotrophic hyphae. Plant autofluorescence is well documented and is even used as a reporter of disease resistance responses (Chaerle et al. 2007; Yu et al. 1998). However, it is of special concern when localizing secreted fungal proteins during plant infection because these proteins are expected to accumulate outside of the fungus. In particular, it is reasonable to suppose that appressoria could secrete proteins that diffuse into cell walls and intercellular spaces and, in such circumstances, it may be difficult to distinguish bona fide fungal protein accumulation from cell wall autofluorescence. In addition, we found that the autofluorescence was often highly sporadic in nature. For example, it was seen in only $30 \%$ of images captured in the RFP detection channel. It follows that the correct interpretation of cell wall fluorescence patterns requires imaging of multiple fusionexpressing transformants together with numerous untransformed controls or the use of spectral scanning to distinguish autofluorescence from protein-derived signals.

It is also well known that some fungi are bioluminescent (Desjardin et al. 2008) while others exhibit autofluorescence under UV light (Wu and Warren 1984; Zizka and Gabriel 2006). Such behavior has not been documented previously for $M$. oryzae, yet we observed strong autofluorescence signals in appressoria and germ tubes. The appressorial fluorescence was first seen in transformants expressing histone::GFP and the signal intensity was very similar to the GFP-labeled nuclei. This could have led to the erroneous conclusion that they were unusually shaped nuclei had control images not been acquired. Autofluorescence was detected in all appressoria at 18 and 36 $\mathrm{h}$ postinoculation. In contrast, the germ tubes produced signals in a sporadic manner. Because we have been unable to reproduce this observation consistently, we suspect that either it is due to a chemical contaminant in the system which stimulates the germ tubes to synthesize a fluorescent compound, or the contaminant itself is fluorescent and bound strongly to cell wall components. Either way, the occurrence of intermittent or unexpected patterns of fungal autofluorescence illustrates the critical importance of including wild-type, untransformed strains in each and every localization experiment.

\section{Use of pFPL vectors for dual labeling.}

A complementary set of vectors based on geneticin resistance was created with the primary goal of labeling strains that already carried one FP marker. Being Gateway cloning compatible, the geneticin vectors easily accept protein::FP cassettes from the intermediate pDONR clones. This is extremely useful when one wishes to colocalize two proteins identified in an initial high-throughput screen. For example, if one has performed initial screening in the pFPL vector, one simply has to mobilize one of the fusion cassettes from the pDONR entry clone into a pFPL-g vector sporting a different FP tag. The resulting construct can then be used to retransform a strain carrying the other protein:FP cassette. This strain should already be available from the initial protein localization screen.

The utility of complementary sets of pFPL plasmids extends beyond dual labeling. Some fungi are naturally resistant to hygromycin; Neurospora tetrasperma is an example (Bhat et al. 2004). In such cases, the geneticin resistance-based vectors should be viable alternatives. Additionally, the availability of a dual-vector system allows one to introduce a fluorescently tagged protein into a gene knockout strain to monitor the effect of a specific mutation on protein localization.

When using related plasmids to retransform strains that are already transgenic it is important to note that this can result in an extremely high frequency of homologous recombination, in which the second vector is targeted to the original plasmid (approximately $80 \%$ in Leptosphaeria maculans) (Farman and 

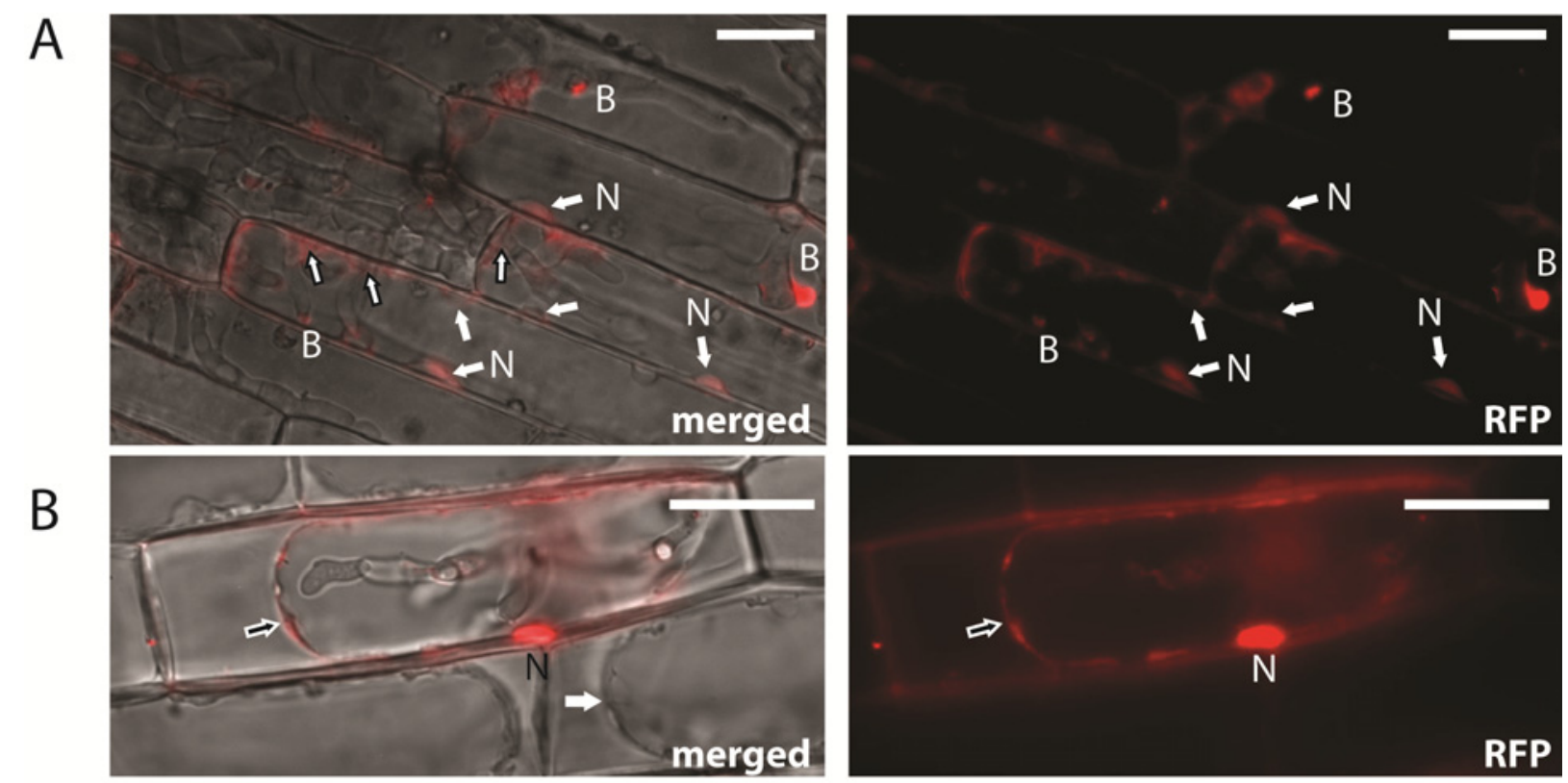

C
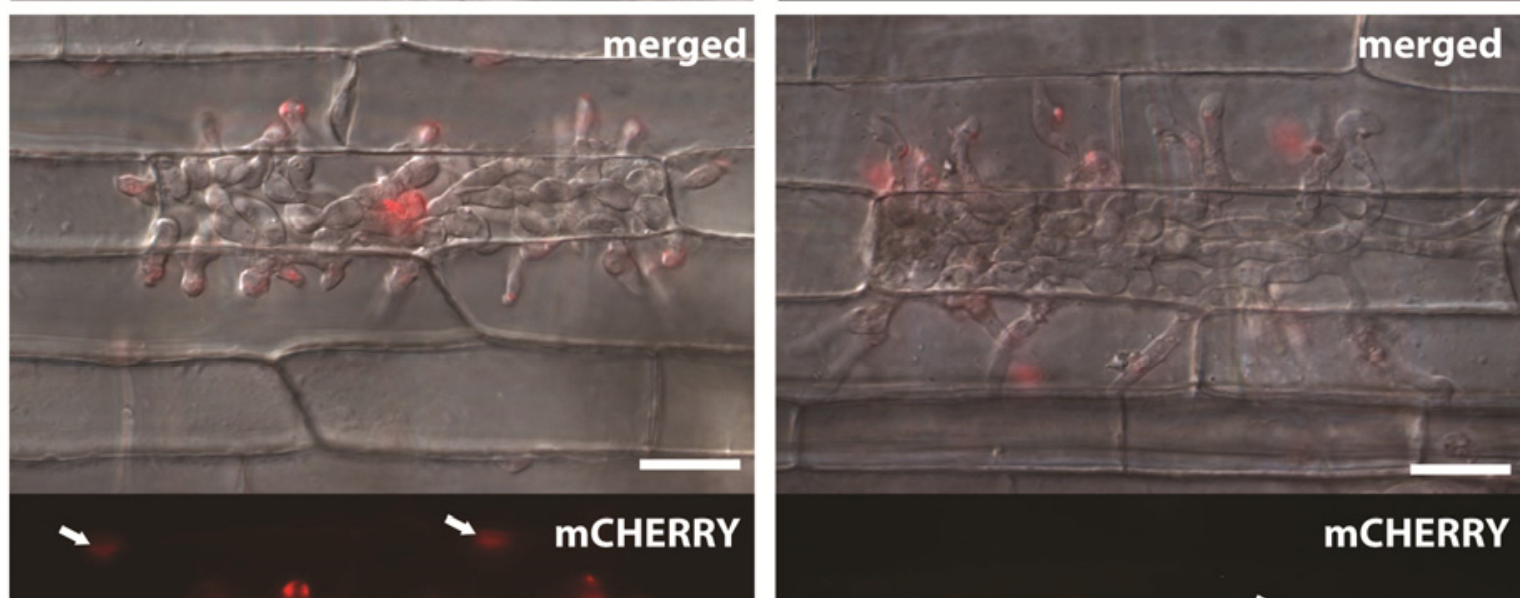

$\rightarrow$
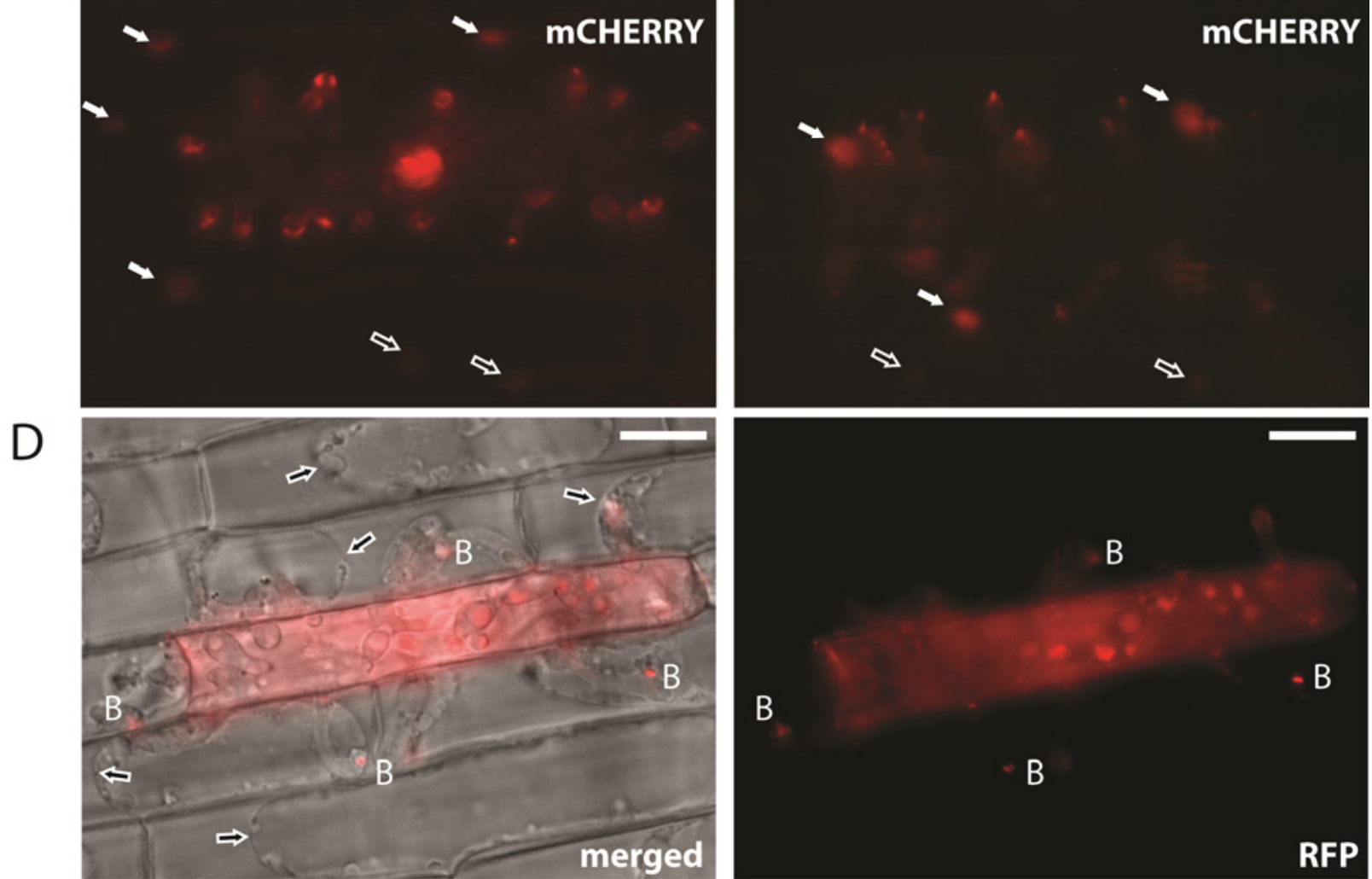
Oliver 1992). With linear DNA fragments, this can result in frequent replacement of the integrated sequences $(>90 \%$ in M. oryzae) (M. Farman, unpublished data). It was for this reason that we used a different promoter to drive the expression of the geneticin resistance gene. Likewise, the reversed orientation of the RFP gene in pFPL-Rh, along with the lack of sequence similarity between RFP and GFP, should help to prevent homologous recombination. Otherwise, most of the second-round transformation events would probably occur via simple marker exchange without attendant integration of the second tagged gene. With this in mind, it is worth remembering that the CFP, GFP, and YFP genes all have very similar sequences. Therefore, if they are to be combined in dual-labeling experiments, it is prudent to apply dual selection during the second round of transformation to ensure retention of the original transgene. Even then, one might experience a very low transformation frequency due to the tendency for targeted replacements. For similar reasons, fluorescently tagged proteins should be introduced into gene knockout strains, as opposed to vice versa.

\section{Screening for candidate effector proteins.}

Together with our novel touchdown PCR protocol, the streamlined Gateway cloning procedure allowed a single person to manage the simultaneous generation of more than 200 protein fusions without any trouble. This level of throughput, along with the robust workflow, opens up the possibility of large-scale screening for candidate effectors based on protein localization patterns during natural plant infection. Cytoplasmic effectors are thought to translocate across host membrane into the host cytoplasm, while apoplastic effectors remain in the extracellular compartment. It follows that a key indicator of possible cytoplasmic effector function is fungal protein accumulation within the plant cytoplasm. A number of criteria must be satisfied before one can reliably conclude that a candidate effector is truly secreted and translocated across an intact plant membrane as part of the normal infection process. Specifically, one must i) demonstrate that the relevant gene is actually expressed by the fungus during the appropriate infection stage (i.e., biotrophic hyphae in Magnaporthe spp.), ii) establish that the protein is secreted from the fungus into the plant tissue, iii) directly detect fungal protein fluorescence in the cytoplasm or organelles of host cells by quantitative analysis of multiple infection sites, and iv) confirm that the host cells are living and that the integrity of the plant plasma membrane and the extrainvasive hyphal membrane (EIHM) enclosing the fungus are not compromised.

The pFPL vectors allowed straightforward and unequivocal identification of candidate effectors, while satisfying all four criteria. Use of the native promoter and analysis of multiple transformants per gene candidate ensured that the fusion con- struct's expression pattern accurately reflected that of the endogenous gene. Thus, if fluorescence was reproducibly observed during plant infection, we could reasonably conclude that the endogenous protein is normally expressed at that time, too. Observation of protein fluorescence anywhere outside of the fungus satisfied criterion ii, while accumulation within the host cell cytoplasm satisfied both criteria ii and iii. Finally, a routine plasmolysis assay allows one to test for plasma membrane integrity (criterion iv).

When interpreting in planta protein localization patterns, it is important to remember that mature plant cells possess a large central vacuole and the cytoplasm is compressed into a thin layer against the cell wall. Therefore, proteins with true cytoplasmic accumulation patterns produce patchy fluorescence almost exclusively at the cell periphery (Fig. 5A). Moreover, invaded host cells retain the ability to plasmolyze, and their cytoplasms and vacuoles usually retain their respective peripheral and central positions (Fig. 5B), even in cells with fairly advanced infections. This is an important point because the images presented in many published effector protein translocation studies show fluorescence distributed evenly throughout the cell lumen (Dou et al. 2008; Kale et al. 2010; Tyler et al. 2013; Whisson et al. 2007). In our experience, encroachment of the cytoplasm into the luminal space occupied by the central vacuole only occurred in cells that failed to plasmolyze, indicating that the plasma membrane had been damaged and the invaded cells were likely dead or dying (Fig. 5D). In the absence of any supporting plasmolysis data, one has to conclude that the above-referenced studies were looking at either dead cells or protein accumulation in the upper or lower cell wall (i.e., apoplast). Kankanala and associates (2007) previously reported that the first invaded cells were dead by the time invasive hyphae had moved into neighboring cells. The Msp1p fluorescence patterns shown here (Figs. 5D) confirm this conclusion. We have also observed even, lumenal staining in cells where the hyphae have yet to escape (data not shown), which suggests that host cell death occurs before the fungus advances into adjacent cells.

Even with plasmolysis, the appearance of cytoplasmic fluorescence in cells with advanced infections should be interpreted with caution if only small numbers of infection sites are observed. As an example, during early and midbiotrophic growth in most invaded host cells, the prototypical apoplastic (i.e., nontranslocated) effector Bas $4 p$ is generally restricted to and evenly distributed within the apoplastic space between the fungal cell wall and the EIHM and it completely outlines the intracellular hyphae (Khang et al. 2010; Mosquera et al. 2009). Typically, Bas4p shows no sign of accumulation inside the host cell cytoplasm, even when fused to the mCherry:NLS reporter construct to concentrate the translocated effectors in the host nucleus (Khang et al. 2010). The occasional detection

Fig. 5. pFPL vectors for the detection of fungal protein delivery into rice cells. A, At approximately 36 h postinoculation (hpi), MGG_02546::RFP accumulated in biotrophic interfacial complexes (BIC) (labeled "B"); in host cytoplasm at the base of hyphae, where they entered second cells (white arrows with black outlines); and in cytoplasmic blebs that were well separated from fungal hyphae (plain white arrows). Note that the tonoplast appears intact around the blebs (black arrows). Possible nuclear accumulation is noted with "N". B, Confirmation of membrane integrity via plasmolysis approximately 28 hpi. The tissue section was plasmolyzed by adding $0.25,0.5$, and $0.75 \mathrm{M}$ sucrose drops in sequential fashion to the edge of the slide. MGG_02546::RFP is present within the protoplast balloon formed during plasmolysis (black arrow with white border). Possible nuclear accumulation is noted with an "N." A protoplast balloon in a neighboring cell is marked with a white arrow. C, Use of pFPNL1 to detect fungal protein delivery into the host cell nucleus. Pwl2:mCherry:NLS fusion proteins (under control of the native PWL2 promoter) were generated using pFPNL1 (plasmid pBV995, left-hand panel) and a conventional restriction enzyme-mediated ligation cloning method (pBV591, right-hand panel). Magnaporthe oryzae transformants individually expressing each construct were inoculated on rice sheaths and observed at 43 to 44 hpi. Both fusion proteins were detected in hyphal tip BIC in the newly invaded cells and in rice nuclei of invaded (filled arrows) and uninvaded neighboring cells (empty arrows). D, Fungal protein accumulation in a dead host cell. Images show a section of plasmolyzed rice leaf sheath approximately 40 hpi with an $M$. oryzae transformant expressing the MGG_05344 (Msp1)::RFP fusion protein. Plasmolysis is clearly evident in the newly invaded cells and their uninfected neighbors (black arrows with white borders) but is absent in the initial infected cell. MSP1::RFP labels several BIC in the surrounding invaded cells ("B"). All images were generated using epifluorescence microscopy. Merged images show the fluorescence signals superimposed over differential interference contrast images. Scale bars $=20 \mu \mathrm{m}$. 
of Bas $4 p$ in the cytoplasm of plasmolyzed cells is often accompanied by a transition from a uniform "outlining" pattern to punctate fluorescence (Mosquera et al. 2009; Khang et al. 2010). Here, we show that punctate staining rapidly accompanies experimentally induced, catastrophic membrane destruction. Thus, it is reasonable to conclude that patchy fluorescence of otherwise apoplastic effectors is an indicator of a compromised membrane.

In the light of our extensive experience in imaging translocated effectors, we strongly recommend that conclusions of effector translocation be based on careful quantification of outcomes at individual infection sites and the use of plasmolysis to differentiate between true translocation and localization artifacts due to damaged host membranes. Finally, it should be noted that plasmolysis tests are so easy to perform that they should be standard for all in planta protein localization experiments.

In conclusion, the pFPL and related vectors represent the first tools for high-throughput protein localization in fungi. These vectors should be suitable for protein localization studies in many fungal species, because they are based on widely used drug resistance cassettes. To date, they have been shown to function in Colletotrichum spp. (Kleemann et al. 2012) (L. Vaillancourt, unpublished data) and Epichlöe festucae (C. Schardl, unpublished data).

\section{MATERIALS AND METHODS}

\section{pFPL vector construction.}

$p F P L-G h$ and $p F P L-C h$. The GFP and CFP genes were amplified from vectors pSITE-2NA and pSITE-1NB (Chakrabarty et al. 2007), respectively, using primers pSITE2B_F and pSITE2B_R (Supplementary Table S3). The PCR products were digested with SacI plus BamHI and the two genes were ligated to plasmid pAN7-2 that had been digested with the same enzyme combination. This placed the $A$. nidulans TrpC promoter downstream of the FP genes. The resulting pAN-pSITE plasmids were digested with SacI plus $\mathrm{Xba \textrm {I }}$ and ligated to correspondingly treated pBHt2 (Mullins et al. 2001), generating pFPL-Gh and pFPL-Ch.

pFPL-Yh. A YFP gene:: $\beta$-tubulin terminator cassette was amplified from pBV231 (Mosquera et al. 2009) using primers pSITE_fusion_F and pBV231_3'R. At the same time, the Gateway cloning cassette was amplified from pSITE-2NB (Chakrabarty et al. 2007) with the primers pSITE2B_F and pSITE2B_R. The products from the two reactions were then used as templates for overlap PCR using primers pSITE_F and pBV231_3'R. The fusion PCR product was then digested with HindIII plus $\mathrm{XbaI}$ and ligated to $\mathrm{pBHt} 2$ cut with the same enzymes, producing plasmid pFPL-Yh.

$p F P L-R h$. The RFP gene was amplified from pSITE-4NB (Chakrabarty et al. 2007) using primers pSITE_fusion_F and pRFP_R. The PCR product was mixed with the Gateway cassette PCR product described in the previous paragraph. Overlap PCR with the pSITE2B_F and pRFP_R primers produced a $2.8-\mathrm{kb}$ fusion product that was then digested with HindIII and $B g l \mathrm{II}$ and ligated in front of a TrpC terminator fragment cloned in pBluescript. The 3.5-kb Gateway::RFP::TrpC terminator cassette was then excised with HindIII and $\mathrm{XbaI}$ and ligated to pBHt 2 that had been cut with the same enzymes, creating the plasmid pFPL-Rh.

pFPNL1. The mCHERRY gene with a $3^{\prime}$ NLS was amplified using plasmid pBV579 (Khang et al. 2010) as template along with the primers mCHERRY_F and mCHERRY:: NLS_3'. The PCR product was digested with ApaI and BamHI and then ligated to an $A p a I$ to $X b a I$ fragment from pFPL-G1 (vector backbone) and a BamHI to $\mathrm{XbaI}$ fragment containing the A. nidulans TrpC terminator. $p F P L$ series $g$ vectors. The $\mathrm{pFPL}$ vector series was duplicated in a new Agrobacterium-based vector conferring geneticin resistance (pBHt3). The recipient $\mathrm{pBHt} 3$ vector was constructed as follows. PCR was used to introduce an NcoI site at the start codon of the G418 resistance gene, which was derived from plasmid pII99 (Namiki et al. 2001). The PCR product was ligated to an EcoRI plus NcoI-digested GAPDH promoter fragment from pMLF2 (An et al. 1996) and the whole promoter-selectable marker cassette was subsequently amplified using the GAPDH_F and G418_R primers. The resulting $\mathrm{P}_{\mathrm{GAPDH}}:: \mathrm{G} 418$ cassette was digested with SacI and BamHI and ligated to pBluescript cut with the same enzymes. The cassette was excised from the pBluescript subclone as an SacI to EcoRV fragment and ligated into pBHt2 cut with $S a c$ I plus $X m n I$, producing $\mathrm{pBH} 3$. Geneticin resistance-based versions of the pFPL vectors were then generated by digesting pBHt3 with $S a c \mathrm{I}$ and $\mathrm{XbaI}$ and ligating this vector backbone fragment separately to each of the four FP Gateway cassettes, which were released from the respective vectors using the same enzyme pair. The resulting vectors are identified by the " $g$ " suffix (e.g., pFPL-Gg).

\section{Amplification of secreted protein genes.}

A web tool named the Gene Fusion Design tool v1.0 was established to facilitate the design of reverse primers starting at the last codon before the stop in each of the genes under study. The designer allows the user to enter multiple gene identifiers into the search box, along with the desired melting temperature and length of promoter sequence to be included in the final PCR product. The output for each gene includes the sequence of the $3^{\prime}$ oligonucleotide, its predicted melting temperature (calculated using the formula $[\mathrm{Tm}=4(\mathrm{G}+\mathrm{C})+2(\mathrm{~A}$ $+\mathrm{T})$ ]) and the sequence of the gene plus promoter. This allows the user to design the $5^{\prime}$ primer manually, or to use the sequence as input for a primer design program such as Primer 3 (Rozen and Skaletsky 2000). For the present study, approximately $1 \mathrm{~kb}$ of upstream promoter sequence was included. The half-attB1 sequence $5^{\prime}$ AAAAAGCAGGCTTA3' was prepended to each $5^{\prime}$ primer and $5^{\prime}$ AGAAAGCTGGGTA $3^{\prime}$ was prepended to the $3^{\prime}$ primers.

For robust amplification of multiple genes in high-throughput fashion, a novel touchdown PCR procedure was employed. The basic cycling conditions were as follows: $94^{\circ} \mathrm{C}, 1 \mathrm{~min}$; initial annealing temperature of $56^{\circ} \mathrm{C}$ (decreasing by $0.2^{\circ} \mathrm{C}$ per cycle over the entire reaction of 25 cycles), $1 \mathrm{~min}$; and $72^{\circ} \mathrm{C}, 1$ $\mathrm{min} / \mathrm{kb}$ of expected product length. An initial 5-min denaturation step at $94^{\circ} \mathrm{C}$ preceded the first cycle and a 10-min extension phase at $72^{\circ} \mathrm{C}$ followed the final cycle. PCR was performed in multiwall plates after grouping together genes with similar sizes. The amplicons were gel purified (Qiagen) and sequenced to confirm their identity. After confirmation, the primary amplicons were used as templates for a second round of PCR whose purpose was to add the full-length attB sequences for subsequent Gateway cloning. Primers used in this step were attB_F 5' GGGGACAAGTTTGTACAAAAAAGC AGGCT 3' and attB_R 5' GGGGACCACTTTGTACAAGAA AGCTGGGT 3'. The final amplicons were gel purified prior to use for Gateway cloning.

\section{Gateway cloning.}

The Gateway cloning procedure was modified to streamline the high-throughput process and to reduce costs. Specifically, the entry and destination clones were generated in a single reaction tube and the quantities of reagents were significantly reduced. Briefly, $1 \mu \mathrm{l}$ of PCR product was added to $1 \mu \mathrm{l}$ of pDONR (100 ng) and $0.4 \mu \mathrm{l}$ of BP clonase. The reaction was allowed to proceed for $2 \mathrm{~h}$ before adding $1 \mu \mathrm{l}$ of the appropriate 
pFPL vector plus $0.4 \mu \mathrm{l}$ of LR clonase and continuing the reaction overnight at room temperature. The reaction was stopped by adding $0.5 \mu \mathrm{l}$ of proteinase $\mathrm{K}$ and heating at $37^{\circ} \mathrm{C}$ for $10 \mathrm{~min}$. The reaction was subjected to a 1:10 dilution and $1 \mu \mathrm{l}$ was used to transform Escherichia coli strain EPI300 (Epicentre Technologies, Madison, WI, U.S.A.) by electroporation or a standard heat shock procedure. The transformation mix was divided into two equal parts: one was plated on $\mathrm{LB}+$ kanamycin $(50 \mu \mathrm{g} / \mathrm{ml})$ to recover the FP-tagged destination clones, while the other part was plated on LB $(50 \%$ salt $)+$ zeocin $(50 \mu \mathrm{g} / \mathrm{ml})$ to recover the entry clones. Three colonies were picked for each transformation and successful creation of the fusion clones was verified via colony PCR using gene-specific forward primers and an FP reverse primer. The validated fusion constructs were then used to transform Agrobacterium tumefaciens AGL1 cells via freezethaw or electrotransformation procedures.

\section{Fungal culture and}

\section{A. tumefaciens-mediated transformation.}

A. tumefaciens AGL1 strain containing the appropriate binary vector was activated from a frozen stock $48 \mathrm{~h}$ before harvesting the $M$. oryzae spores to be used for transformation. The M. oryzae strain used in all experiments was O-137 (wild type) and was activated from a fresh (nonsubcultured) stock. The fungus was grown on oatmeal agar amended with ampicillin at $100 \mu \mathrm{g} / \mathrm{ml}$ and $25^{\circ} \mathrm{C}$ under constant white light for 7 to 10 days. Conidia were harvested, filtered through one layer of Miracloth (Calbiochem) and then quantified and diluted to a density of $1 \times 10^{6}$ spores $/ \mathrm{ml}$. The Agrobacterium vir genes were induced by growing in LB supplemented with $0.2 \mathrm{mM}$ of acetosyringone and cocultivation was started when the culture reached an optical density at $660 \mathrm{~nm}$ of 0.5 to 0.7 . Cocultivation was initiated by mixing $200 \mu \mathrm{l}$ of induced Agrobacterium with $200 \mu \mathrm{l}$ of spore suspension and plating onto induction medium agar (0.04 $\mathrm{M}$ morpholinoethanesulfonic acid [pH 5.3] $5 \mathrm{mM}$ glucose, $0.5 \%$ glycerol, $1.5 \%$ agar, $0.2 \mathrm{mM}$ acetosyringone, and thiamin at $1 \mathrm{ppm}$ ) covered with sterile pieces ( 2 by 2 $\mathrm{cm}$ ) of black filter paper. After $48 \mathrm{~h}$ of incubation at room temperature, the paper squares were transferred to complete medium agar $(1 \%$ glucose, $0.6 \%$ yeast extract, $0.6 \%$ casamino acids, thiamin at $1 \mathrm{ppm}$, and $1.5 \%$ agar) supplemented with cefotaxime $(200 \mu \mathrm{g} / \mathrm{ml})$, carbenicillin $(250 \mu \mathrm{g} / \mathrm{ml})$, and hygromycin B $(100 \mu \mathrm{g} / \mathrm{ml})$. Two to three days post transfer, the $M$. oryzae transformants (12 isolates per gene construct) were picked into 24-well plates containing oatmeal agar plus hygromycin B $(200 \mu \mathrm{g} / \mathrm{ml})$. Of the 12 transformants, 6 were streaked on water agar plus hygromycin B at $100 \mu \mathrm{g} / \mathrm{ml}$ for single-spore isolation and the remainder were stored as backup stocks. Single germinated spores were transferred to oatmeal agar plus hygromycin B $(100 \mu \mathrm{g} / \mathrm{ml})$ in individual wells of a 12-well petri dish. The primary and single-spored transformants were stored by allowing them to grow into sterile filter paper squares that had been placed on the surface of the oatmeal agar culture medium, drying the paper in a biological safety cabinet, and maintaining the paper squares at $-20^{\circ} \mathrm{C}$.

For the protein localization studies, at least five isolates per tagged genes were retrieved from storage and transferred to 60 -mm petri dishes with oatmeal agar containing hygromycin $\mathrm{B}$ at $100 \mu \mathrm{g} / \mathrm{ml}$. The cultures were grown for 5 days at $22^{\circ} \mathrm{C}$ under constant fluorescent light to generate the spores for infection studies.

\section{Rice inoculation and cytological observation.}

Leaf sheaths from 4- to 5-week-old plantlets of the highly susceptible rice lines 51583 and YT-16 were used for inoculations. The sheaths were prepared by cutting the pseudostems at soil level and the preemergent inner leaves were removed to leave a hollow, outer leaf sheath (Koga et al. 2004). This was then cut into approximately $10-\mathrm{cm}$ sections and, for each transformant, approximately $100 \mu \mathrm{l}$ of spore suspension $(2 \times$ $10^{4}$ spores $/ \mathrm{ml}$ in $0.25 \%$ gelatin) was pipetted into the middle compartment of five to seven leaf sheath sections. The inoculated sheaths were placed into deep petri dishes where they were supported by inverted two-by-eight PCR strips; they were positioned so as to allow the spores to settle onto the midveins. Sufficient distilled water was added to the petri dishes to maintain a high moisture environment and incubation was performed at room temperature (approximately $25^{\circ} \mathrm{C}$ ) in the dark.

Cytological observations were performed on spores $(0 \mathrm{~h})$ as well as inoculated tissues 18 to 24 and approximately $36 \mathrm{~h}$ postinoculation. For on or in planta assays, a scalpel was used to slice the leaf longitudinally to expose the midvein; then, slices were removed from either side of the midvein to remove the green external epidermis. Finally, the scalpel was inserted transversely through the section just beneath and parallel to the inner epidermal layer, and an epidermal strip two to three cell layers thick was sliced off. The strips were mounted directly on microscope slides in a small volume of water. A minimum of two transformants were analyzed per construct and multiple images of a nontransformed control strain were acquired in every localization experiment.

\section{Microscopy.}

Microscopy was performed using Zeiss Axioplan 2 and Axioplan 2 IE MOT epifluorescence microscopes and an Olympus FV1000 confocal microscope. Epifluorescence images were acquired on the Axioplan 2 unless specifically noted below. The Axioplan 2 is equipped with a Zeiss 50-W HBO AC mercury lamp source and uses the following filters: eGFP, excitation (ex.) $470 \pm 20 \mathrm{~nm}$, emission (em.) $540 \pm 20 \mathrm{~nm}$; eCFP, ex. $436 \pm 10 \mathrm{~nm}$, em. $480 \pm 20 \mathrm{~nm}$; eYFP, ex. $500 \pm 10 \mathrm{~nm}$, em. $535 \pm 15 \mathrm{~nm}$; and mRFP or mCHERRY, ex. $546 \pm 6 \mathrm{~nm}$, em. $650 \pm 37.5 \mathrm{~nm}$. The Axioplan 2 IE MOT used 100-W FluoArc or an X-Cite 120 (EXFO Life Sciences) mercury lamp source and was equipped with the following filters: GFP, ex. $480 \pm 20$ nm, em. $510 \pm 10 \mathrm{~nm}$ (Fig. 4, MGG_09470 and MGG_10914, direct fusions) and mCHERRY, ex. $535 \pm 35 \mathrm{~nm}$, em. $610 \pm 32$ $\mathrm{nm}$ (Fig. 5D, right-hand panel). Imaging on the FV1000 confocal microscope used a PLAPO $\times 40$ WLSM objective. Excitation and emission wavelengths were 488 and $510 \mathrm{~nm}$, respectively, for eGFP and 543 and $581 \mathrm{~nm}$, respectively, for mRFP.

\section{Southern hybridization analysis.}

DNA $(1 \mu \mathrm{g})$ from representative transformants was digested with restriction enzymes and then fractionated by agarose gel electrophoresis, followed by electroblotting (Genie Electroblotter, Idea Scientific, MN, U.S.A.) to Pall Biodyne B membranes. The DNA was affixed to the membrane by alkali treatment and UV crosslinking and then probed with a BamHI to $X b a I$ fragment encompassing the entire TrpC terminator using a previously published protocol (Thornbury and Farman 2000). The blots were washed to remove nonspecific hybridization and then exposed to phosphorimage screens. After overnight exposure, the screens were scanned in a Typhoon phosphorimager (GE Healthcare, Little Chalfont, U.K.).

\section{ACKNOWLEDGMENTS}

This project was supported by Agriculture and Food Research Initiative Competitive Grants Program Grant number 2008-35600-18809 from the United States Department of Agriculture National Institute of Food and Agriculture. This is contribution number 14-255-J from the Agricultural Experiment Station at Kansas State University and contribution number 14-12-080 from the Agricultural Experiment Station at the University of Kentucky, published with the approval of the station director. 


\section{LITERATURE CITED}

An, Z., Farman, M. L., Budde, A., Taura, S., and Leong, S. A. 1996. New cosmid vectors for library construction, chromosome walking and restriction mapping in filamentous fungi. Gene 176:93-96.

Bhat, A., Tamuli, R., and Kasbekar, D. P. 2004. Genetic transformation of Neurospora tetrasperma, demonstration of repeat-induced point mutation (RIP) in self-crosses and a screen for recessive RIP-defective mutants. Genetics 167:1155-1164.

Bourett, T. M., Sweigard, J. A., Czymmek, K. J., Carroll, A., and Howard, R. J. 2002. Reef coral fluorescent proteins for visualizing fungal pathogens. Fungal Genet. Biol. 37:211-220.

Chaerle, L., Lenk, S., Hagenbeek, D., Buschmann, C., and Van Der Straten, D. 2007. Multicolor fluorescence imaging for early detection of the hypersensitive reaction to tobacco mosaic virus. J. Plant Physiol. 164:253-262.

Chakrabarty, R., Banerjee, R., Chung, S. M., Farman, M., Citovsky, V., Hogenhout, S. A., Tzfira, T., and Goodin, M. 2007. pSITE vectors for stable integration or transient expression of autofluorescent protein fusions in plants: Probing Nicotiana benthamiana-virus interactions. Mol. Plant-Microbe Interact. 20:740-750.

Chen, S., Songkumarn, P., Venu, R.C., Gowda, M., Bellizzi, M., Hu, J., Liu, W., Ebbole, D., Meyers, B., Mitchell, T., and Wang, G. L. 2013. Identification and characterization of in planta-expressed secreted effector proteins from Magnaporthe oryzae that induce cell death in rice. Mol. Plant-Microbe Interact. 26:191-202.

Choi, J., Park, J., Jeon, J., Chi, M. H., Goh, J., Yoo, S. Y., Jung, K., Kim, H., Park, S. Y., Rho, H. S., Kim, S., Kim, B. R., Han, S. S., Kang, S., and Lee, Y. H. 2007. Genome-wide analysis of T-DNA integration into the chromosomes of Magnaporthe oryzae. Mol. Microbiol. 66:371-382.

Choi, J., Park, J., Kim, D., Jung, K., Kang, S., and Lee, Y. H. 2010. Fungal secretome database: Integrated platform for annotation of fungal secretomes. BMC Genomics 11:105.

Dagdas, Y. F., Yoshino, K., Dagdas, G., Ryder, L. S., Bielska, E., Steinberg, G., and Talbot, N. J. 2012. Septin-mediated plant cell invasion by the rice blast fungus, Magnaporthe oryzae. Science 336:1590-1595.

Desjardin, D. E., Anderson, G. O., and Stevani, C. V. 2008. Fungi bioluminescence revisited. Photochem. Photobiol. Sci. 2008:170-182.

Dietzgen, R. G., Martin, K. M., Anderson, G., and Goodin, M. M. 2012. In planta localization and interactions of impatiens necrotic spot tospovirus proteins. J. Gen. Virol. 93:2490-2495.

Dou, D., Kale, S. D., Wang, X., Jiang, R. H. Y., Bruce, N. A., Arredondo, F. D., Zhang, X., and Tyler, B. M. 2008. RXLR-mediated entry of Phytophthora sojae effector Avr1b into soybean cells does not require pathogen-encoded machinery. Plant Cell 20:1930-1947.

Farman, M. L., and Oliver, R. P. 1992. Transformation frequencies are enhanced and vector DNA is targeted during retransformation of Leptosphaeria maculans, a fungal plant pathogen. Mol. Gen. Genet. 231:243247.

Felle, H. H. 1998. The apoplast $\mathrm{pH}$ of the Zea mays root cortex as measured with $\mathrm{pH}$-sensitive microelectrodes: Aspects of regulation. J. Exp. Bot. 49:987-995.

Gao, D., Knight, M. R., Trewavas, A. J., Sattelmacher, B., and Plieth, C. 2004. Self-reporting Arabidopsis expressing $\mathrm{pH}$ and $[\mathrm{Ca} 2+]$ indicators unveil ion dynamics in the cytoplasm and in the apoplast under abiotic stress. Plant Physiol. 134:898-908.

Grignon, C., and Sentenac, H. 1991. $\mathrm{pH}$ and ionic conditions in the apoplast. Annu. Rev. Plant Physiol. Plant Mol. Biol. 42:103-128.

Hartley, J. L., Temple, G. F., and Brasch, M. A. 2000. DNA cloning using in vitro site-specific recombination. Genome Res. 10:1788-1795.

He, M., Kershaw, M. J., Soanes, D., Xia, Y., and Talbot, N. J. 2012. Infection-associated nuclear degeneration in the rice blast fungus Magnaporthe oryzae requires non-selective autophagy. PLoS One 7:e33270.

Hesse, S. J., Ruijter, G. J., Dijkema, C., and Visser, J. 2002. Intracellular $\mathrm{pH}$ homeostasis in the filamentous fungus Aspergillus niger. Eur. J. Biochem. 269:3485-3494.

Jackson, J. C., Higgins, L. A., and Lin, X. 2009. Conidiation color mutants of Aspergillus fumigatus are highly pathogenic to the heterologous insect host Galleria mellonella. PLoS One 4:e4224.

Jeong, J. S., Mitchell, T. K., and Dean, R. A. 2007. The Magnaporthe grisea snodprot1 homolog, MSP1, is required for virulence. FEMS (Fed. Eur. Microbiol. Soc.) Microbiol. Lett. 273:157-165.

Jeong, R.-D., Chandra-Shekara, A. C., Barman, S. R., Navarre, D., Klessig, D. F., Kachroo, A., and Kachroo, P. 2010. Cryptochrome 2 and phototropin 2 regulate resistance protein-mediated viral defense by negatively regulating an E3 ubiquitin ligase. Proc. Natl. Acad. Sci. U.S.A. 107:13538-13543.

Jiang, R. H., Tripathy, S., Govers, F., and Tyler, B. M. 2008. RXLR effector reservoir in two Phytophthora species is dominated by a single rapidly evolving superfamily with more than 700 members. Proc. Natl.
Acad. Sci. U.S.A. 105:4874-4879.

Kale, S. D., Gu, B., Capelluto, D. G., Dou, D., Feldman, E., Rumore, A., Arredondo, F. D., Hanlon, R., Fudal, I., Rouxel, T., Lawrence, C. B., Shan, W., and Tyler, B. M. 2010. External lipid PI3P mediates entry of eukaryotic pathogen effectors into plant and animal host cells. Cell 142:284-295.

Kankanala, P., Czymmek, K., and Valent, B. 2007. Roles for rice membrane dynamics and plasmodesmata during biotrophic invasion by the blast fungus. Plant Cell 19:706-724.

Kemski, M. M., Stevens, B., and Rappleye, C. A. 2013. Spectrum of TDNA integrations for insertional mutagenesis of Histoplasma capsulatum. Fungal Biol. 117:41-51.

Kershaw, M. J., and Talbot, N. J. 2009. Genome-wide functional analysis reveals that infection-associated fungal autophagy is necessary for rice blast disease. Proc. Natl. Acad. Sci. U.S.A. 106:15967-15972.

Khang, C. H., Berruyer, R., Giraldo, M.C., Kankanala, P., Park, S. Y., Czymmek, K., Kang, S., and Valent, B. 2010. Translocation of Magnaporthe oryzae effectors into rice cells and their subsequent cell-tocell movement. Plant Cell 22:1388-1403.

Kleemann, J., Rincon-Rivera, L. J., Takahara, H., Neumann, U., van Themaat, E. V. L., van der Does, H. C., Hacquard, S., Stüber, K., Will, I., Schmalenbach, W., Schmelzer, E., and O'Connell, R.J. 2012. Sequential delivery of host-induced virulence effectors by appressoria and intracellular hyphae of the phytopathogen Colletotrichum higginsianum. PLoS Pathog. 8:e1002643.

Koga, H., Dohi, K., Nakayachi, O., and Mori, M. 2004. A novel inoculation method of Magnaporthe grisea for cytological observation of the infection process using intact leaf sheaths of rice plants. Physiol. Mol. Plant Pathol. 64:67-72.

Levy, A., Zheng, J. Y., and Lazarowitz, S. G. 2013. The tobamovirus Turnip vein clearing virus 30-kilodalton movement protein localizes to novel nuclear filaments to enhance virus infection. J. Virol. 87:6428 6440.

Ma, H., Kunes, S., Schatz, P. J., and Botstein, D. 1987. Plasmid construction by homologous recombination in yeast. Gene 58:201-216.

Meng, Y., Patel, G., Heist, M., Betts, M. F., Tucker, S. L., Galadima, N., Donofrio, N. M., Brown, D., Mitchell, T. K., Li, L., Xu, J. R., Orbach, M., Thon, M., Dean, R. A., and Farman, M. L. 2007. A systematic analysis of T-DNA insertion events in Magnaporthe oryzae. Fungal Genet. Biol. 44:1050-1064.

Miyawaki, A., Nagai, T., and Mizuno, H. 2003. Mechanisms of protein fluorophore formation and engineering. Curr. Opin. Chem. Biol. 7:557562.

Mosquera, G., Giraldo, M. C., Khang, C. H., Coughlan, S., and Valent, B. 2009. Interaction transcriptome analysis identifies Magnaporthe oryzae BAS1-4 as Biotrophy-associated secreted proteins in rice blast disease. Plant Cell 21:1273-1290.

Mullins, E. D., Chen, X., Romaine, P., Raina, R., Geiser, D. M., and Kang, S. 2001. Agrobacterium-mediated transformation of Fusarium oxysporum: An efficient tool for insertional mutagenesis and gene transfer. Phytopathology 91:173-180.

Namiki, F., Matsunaga, M., Okuda, M., Inoue, I., Nishi, K., Fujita, Y., and Tsuge, T. 2001. Mutation of an arginine biosynthesis gene causes reduced pathogenicity in Fusarium oxysporum f. sp. melonis. Mol. Plant-Microbe Interact. 14:580-584.

Nyilasi, I., Ács, K., Papp, T., Nagy, E., and Vágvölgyi, C. 2005. Agrobacterium tumefaciens-mediated transformation of Mucor circinelloides. Folia Microbiol. 50:415-420.

Odenbach, D., Thines, E., Anke, H., and Foster, A. J. 2009. The Magnaporthe grisea class VII chitin synthase is required for normal appressorial development and function. Mol. Plant Pathol. 10:81-94.

Park, C.-H., Chen, S., Shirsekar, G., Zhou, B., Khang, C. H., Songkumarn, P., Afzal, A. J., Ning, Y., Wang, R., Bellizzi, M., Valent, B., and Wang, G.-L. 2012. The Magnaporthe oryzae effector AvrPiz-t targets the RING E3 ubiquitin ligase APIP6 to suppress pathogen-associated molecular pattern-triggered immunity in rice. Plant Cell 24:47484762.

Rafiqi, M., Gan, P. H. P., Ravensdale, M., Lawrence, G. J., Ellis, J. G., Jones, D. A., Hardham, A. R., and Dodds, P. N. 2010. Internalization of flax rust avirulence proteins into flax and tobacco cells can occur in the absence of the pathogen. Plant Cell 22:2017-2032.

Rho, H. S., Kang, S., and Lee, Y. H. 2001. Agrobacterium tumefaciensmediated transformation of the plant pathogenic fungus, Magnaporthe grisea. Mol. Cells 12:407-411.

Ribot, C., Césari, S., Abidi, I., Chalvon, V., Bournaud, C., Vallet, J., Lebrun, M.-H., Morel, J.-B., and Kroj, T. 2013. The Magnaporthe oryzae effector AVR1-CO39 is translocated into rice cells independently of a fungal-derived machinery. Plant J. 74:1-12.

Rolland, S., Bruel, C., Rascle, C., Girard, V., Billon-Grand, G., and Poussereau, N. 2009. $\mathrm{pH}$ controls both transcription and post-transla- 
tional processing of the protease BcACP1 in the phytopathogenic fungus Botrytis cinerea. Microbiology 155:2097-2105.

Rozen, S., and Skaletsky, H. 2000. Primer3 on the WWW for general users and for biologist programmers. Methods Mol. Biol. 132:365-386.

Selote, D., and Kachroo, A. 2010. RPG1-B-derived resistance to AvrBexpressing Pseudomonas syringae requires RIN4-like proteins in soybean. Plant Physiol. 153:1119-1211.

Shabab, M., Takayuki, S., Gu, C., Kaschani, F., Pansuriya, T., Chintha, R., Harzen, A., Colby, T., Kamoun, S., and van der Hoorn, R. A. L. 2008. Fungal effector protein AVR2 targets diversifying defense-related cys proteases of tomato. Plant Cell 20:1169-1183.

Shaner, N. C., Steinbach, P. A., and Tsien, R. Y. 2005. A guide to choosing fluorescent proteins. Nat. Methods 2:905-909.

Talhinhas, P., Muthumeenakshi, S., Neves-Martins, J., Oliviera, H., and Sreenivasaprasad, S. 2008. Agrobacterium-mediated transformation and insertional mutagenesis in Colletotrichum acutatum for investigating varied pathogenicity lifestyles. Mol. Biotechnol. 39:57-67.

Thornbury, D. W., and Farman, M. L. 2000. Reusing nylon membranes for radioactive hybridizations. Biotechniques 29:1250-1254.

Tyler, B. M., Kale, S. D., Wang, Q., Tao, K., Clark, H. R., Drews, K., Antignani, V., Rumore, A., Hayes, T., Plett, J. M., Fudal, I., Gu, B., Chen, Q., Affeldt, K. J., Berthier, E., Fischer, G. J., Dou, D., Shan, W., Keller, N. F. M., Rouxel, T., and Lawrence, C. B. 2013. Microbe-independent entry of oomycete RxLR effectors and fungal RxLR-like effectors into plant and animal cells is specific and reproducible. Mol. Plant-
Microbe Interact. 26:611-616.

Whisson, S. C., Boevink, P. C., Moleleki, L., Avrova, A. O., Morales, J. G., Gilroy, E. M., Armstrong, M. R., Grouffaud, S., van West, P., Chapman, S., Hein, I., Toth, I. K., Pritchard, L., and Birch, P. R. J. 2007. A translocation signal for delivery of oomycete effector proteins into host plant cells. Nature 450:115-118.

Wu, C. H., and Warren, H. L. 1984. Natural autofluorescence in fungi, and its correlation with viability. Mycology 76:1049-1058.

Yon, J., and Fried, M. 1989. Precise gene fusion by PCR. Nucleic Acids Res. 17:4895.

Yu, I.-C., Parker, J., and Bent, A. F. 1998. Gene-for-gene disease resistance without the hypersensitive response in Arabidopsis dndl mutant. Proc. Natl. Acad. Sci. U.S.A. 95:7819-7824.

Yu, J.-H., Hamai, Z., Han, K.-H., Seo, J.-A., Reyes-Domínguez, Y., and Scazzochio, C. 2004. Double-joint PCR: A PCR-mased molecular tool for gene manipulations in fungi. Fungal Genet. Biol. 41:973-981.

Zizka, Z., and Gabriel, J. 2006. Primary fluorescence (autofluorescence) of fruiting bodies of the wood-rotting fungus Fomes fomentarius. Folia Microbiol. 51:109-113.

\section{AUTHOR-RECOMMENDED INTERNET RESOURCES}

Addgene, the nonprofit plasmid repository: www.addgene.org Gene Fusion Design tool: fungus.ca.uky.edu/MoryzaeGeneFusions.htm 